\title{
Identification of Key Transport Phenomena in High-Temperature Reactors: Flow and Heat Transfer Characteristics
}

\author{
Georg Liesche $e^{* \dagger}$ and Kai Sundmacher ${ }^{\dagger, \dagger}$ \\ $\dagger$ Max Planck Institute for Dynamics of Complex Technical Systems, Department Process \\ Systems Engineering, Sandtorstr.1, D-39106 Magdeburg, Germany \\ $\ddagger$ Otto-von-Guericke-University Magdeburg, Department Process Systems Engineering, \\ Universitätsplatz 2, D-39106 Magdeburg, Germany \\ E-mail: *liesche@mpi-magdeburg.mpg.de
}

\begin{abstract}
High-temperature reactors are employed to produce key intermediates within the chemical value chain such as synthesis gas and hydrogen cyanide. The drawback of those reactors is their high energy consumption. In practice, intensive simulations, know-how based on experience as well as heuristics are used to optimize those reactors. Knowledge of the key transport phenomena that govern the reactor behavior, however, enables a systematic reactor design and optimization. Using a simplified but effective rigorous two-dimensional reactor model modeling assumptions are scrutinized and key flow and heat transfer phenomena are identified using the case study of synthesis of hydrogen cyanide $(\mathrm{HCN})$. Following the model validation, it is shown that buoyant forces are significant near the walls whereas turbulent flow is negligible. In contrast to estimates using dimensionless numbers both conduction accounting for $81.9 \%$ and radiation with $18.1 \%$ are significant in providing the energy to the reacting gas mixture
\end{abstract}


inside the synthesis compartments. The results demonstrate the importance of a careful model selection for high-temperature reactors and enable a targeted reactor design optimization.

\section{Introduction}

A more sustainable production of goods with a lower carbon footprint is achievable via switching to renewable resources and increasing resource efficiencies. The European chemical industry is highly energy intensive accounting for $19 \%$ of total industrial energy consumption in 2014. ${ }^{1}$ The German society for chemical- and biotechnology estimates that up to 20 to $30 \mathrm{Mt}$ of $\mathrm{CO}_{2}$ emissions can be reduced by efficiency measures and retrofits in this domain. ${ }^{2}$ Energy intensive processes such as endothermic gas phase synthesis reactions are essential within the chemical value chain. Therefore they are attractive targets for process intensification because small improvements of the resource efficiency of the process may cause a potentially large reduction of the ecological footprint. A well-known and intensely investigated example is steam methane reforming (SMR) where research expands from solar reforming to optimization of coupled processes e.g. with a solid oxide fuel cell. ${ }^{3-5}$ For the process intensification of the reforming reactor itself Bhat et al. suggest three principal future directions in their review: ${ }^{6}$ catalytic materials, multiscale modeling and a reduction of heat and mass transfer limitations inside the reactor. In the case of SMR the latter was recently addressed mostly through simulations using commercial computational fluid dynamics codes such as Phoenics or Ansys Fluent. ${ }^{7,8}$ Analysis of the relevant transport phenomena inside the reactor that is modeled with these commercial codes, however, is difficult because the underlying equations cannot be accessed and modified by the user directly. Therefore, the decisions on adequate modeling assumptions are not straightforward.

On the contrary, model selection is not emphasized sufficiently: Yu et al. see radiation as the dominant mode of heat transfer in the compartments between tube loads and furnace accounting for $95 \%$ of overall heat transfer; ${ }^{9}$ this value was subsequently quoted in further 
contributions in the field. ${ }^{10,11}$ Baukal describes the inlet region as radiation dominated and the outlet region as convection dominated. ${ }^{12}$ The books by Specht and Woods rely on zonal models and mention that burners with tube loads should be custom designed. ${ }^{13,14}$ Thus, rules of thumb for design and process intensification of high-temperature catalytic gas phase reactors are scarce.

The objective of this work is to scrutinize physical modeling assumptions and rules of thumb for high-temperature catalytic gas phase reactors critically using a simplified but effective, rigorous modeling approach. The approach is based on solving a system of coupled partial differential equations (PDEs) through discretization and integration in steady state using an in-house code in Matlab and Casadi. ${ }^{15}$ The approach is illustrated with the case study of synthesis of hydrogen cyanide (HCN) from methane and ammonia according to the Degussa route (BMA). ${ }^{16,17}$ This example is selected due to its extreme reaction conditions: the tube surface temperature reaches $1500 \mathrm{~K}$ and the reaction enthalpy of the HCN synthesis reaction is $252 \mathrm{~kJ} / \mathrm{mol}$. Additionally, the process is of high industrial significance because HCN is an intermediate step towards poly(methyl methacrylate) or synthetic methionine and was studied scarcely in the past. ${ }^{18}$ Similar to SMR synthesis reactors for the BMA process consist of two separate compartments: a furnace provides heat to the channels or tubes where the endothermic synthesis occurs (Fig. 1 A). This study focuses on transport phenomena and characteristics of the inner synthesis compartments where flow, heat transfer and chemical reactions are strongly coupled.

\section{Methods}

Reactor geometries vary from tubes to plates in autothermal designs to channels in a monolith. ${ }^{17,19,20}$ The underlying physical transport phenomena, however, are the same and e.g. wall effects for flow or radiation have to be taken into account. ${ }^{21}$ Therefore, the analysis is carried out for channel flow between two parallel plates where two dimensions $-y$ in 


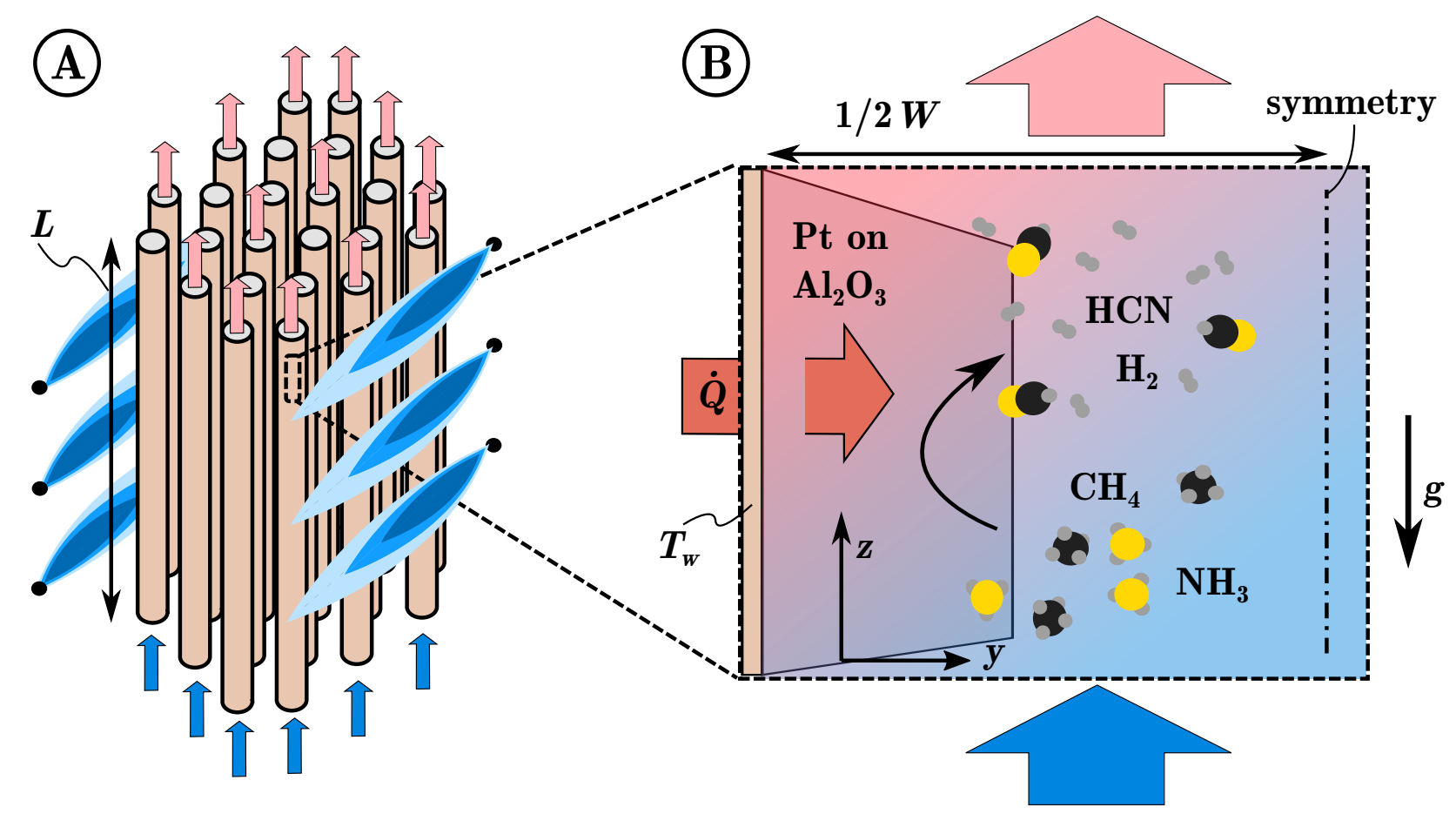

Figure 1: Schematic illustration of a tube-bundle furnace reactor: tube arrangement in bundles inside a combustion chamber where combustion provides the heat to the synthesis tubes (A) and a single synthesis compartment for the simplifying assumption of channel flow (B). The flow direction in (B) is indicated with arrows. ${ }^{17}$

transverse and $z$ along the principle flow direction - suffice as indicated in Fig. 1 B. Buoyancy is taken into account as indicated with the standard gravity $g$ pointing in negative $z$ direction. The analysis is carried out in Matlab to maintain full accessibility of all equations that are involved. For the dimensionless analysis Grashoff (Gr), Reynolds (Re), Planck (N) and Boltzmann (Bo) numbers are used. This section introduces the reactor model and its mathematical solution strategy.

\section{Reactor Model}

\section{Modeling Assumptions}

The channel flow between the plates which is illustrated in Fig. $1 \mathrm{~B}$ is dominated by flow in the $z$-direction. The reactor is in upright orientation with reactants entering at the bottom and products leaving at the top. Reynolds numbers are far higher than one $(\operatorname{Re} \gg 1)$ 
as shown below in Fig. 8 due to the high fluid velocities along $z$. Additionally, gradients in velocity, species concentrations and temperature are more significant in the transverse $y$-direction than in the $z$-direction. Therefore a boundary layer model is selected which means that all transport phenomena are considered in transverse $y$-direction whereas advection dominates transport in the principle flow direction (z-direction). ${ }^{22}$ The reactive flow is modeled in steady-state. An ideal gas assumption is justified by the near-ambient pressure inside the reactor. Laminar and thermally dilatant flow are applied but these assumptions are investigated in more detail in the results section. Radiative heat transfer is accounted for with a participating (absorbing and emitting) medium that is modeled as multiple gray and non-scattering gases between gray walls.

\section{Conservation Laws}

Based on the modeling assumptions, local conservation laws for total mass, species mass, momentum, energy and radiative intensity are formulated as

$$
\begin{aligned}
\frac{\partial}{\partial z}\left(\rho v_{z}\right)+\frac{\partial}{\partial y}\left(\rho v_{y}\right) & =0 \\
\rho v_{z} \frac{\partial w_{\alpha}}{\partial z}+\rho v_{y} \frac{\partial w_{\alpha}}{\partial y} & =-\frac{\partial j_{y, \alpha}}{\partial y}+\sigma_{\alpha} \quad \alpha \in\left[1,2, \ldots, N_{c}\right] \\
\rho\left(v_{z} \frac{\partial v_{z}}{\partial z}+v_{y} \frac{\partial v_{z}}{\partial y}\right) & =-\frac{\partial p}{\partial z}+\frac{\partial \tau^{*}}{\partial y}+\rho g \\
0 & =\frac{\partial p}{\partial y} \\
\rho c_{p}\left(v_{z} \frac{\partial T}{\partial z}+v_{y} \frac{\partial T}{\partial y}\right) & =v_{z} \frac{\partial p}{\partial z}-\frac{\partial q_{y}^{(c)}}{\partial y}-\frac{\partial q_{y}^{(r)}}{\partial y} \\
-\sum_{\alpha=1}^{N_{c}} h_{\alpha}^{0} \sigma_{\alpha} & -\sum_{\alpha=1}^{N_{c}} j_{y, \alpha} \frac{\partial h_{\alpha}^{0}}{\partial y}+\sum_{\alpha=1}^{N_{c}} g j_{y, \alpha}+\tau^{*} \frac{\partial v_{z}}{\partial y} \\
\frac{\mathrm{d} I}{\mathrm{~d} s} & =-\kappa I(s)+\kappa I_{b}(s) \quad s \in \Omega \quad .
\end{aligned}
$$

The density is denoted as $\rho$ and $v_{y}, v_{z}$ are velocities in $y$ and $z$ direction. Mass fractions of component $\alpha$ are indicated as $w_{\alpha}$. Diffusion flux $j_{y, \alpha}$, source term $\sigma_{\alpha}$, modified stress tensor 
$\tau^{*}$ as well as conductive and radiative heat fluxes in $y$ direction $q_{y}^{(c)}, q_{y}^{(r)}$ are discussed below. $T$ and $p$ indicate temperature and pressure whereas $c_{p}$ and $h_{\alpha}^{0}$ denote the heat capacity of the gas mixture and the enthalpy of the pure component $\alpha . I$ and $I_{b}$ denote radiative intensity and radiative intensity of a black body whereas $s, \Omega$ and $\kappa$ represent radiation direction, the set of all possible directions and the radiative absorption coefficient.

As a consequence of the boundary layer formulation, all expressions of the momentum balance in transverse direction $y$ cancel out resulting in constant pressures across $y$ (Eq. (1d)). The energy balance (Eq. (1e)) contains the following terms whose impacts are analyzed below: advection in $z$ and $y$ directions, pressure work, conductive and radiative heat fluxes in $y$ direction, enthalpy change due to chemical reaction, enthalpy diffusion, volume work and the dissipation term.

\section{Thermodynamic Equations of State}

The density is expressed via the ideal gas law. The Shomate equation is selected for heat capacities and enthalpies of single components as a caloric equation of state. ${ }^{23}$ Mixing enthalpies do not exist for ideal gases and therefore pure substance enthalpies $h_{\alpha}^{0}$ are used in the conservation laws above.

\section{Constitutive Equations}

The synthesis reaction of $\mathrm{HCN}\left(\mathrm{R}_{1}\right)$ and decomposition of $\mathrm{NH}_{3}$ into its elements $\left(\mathrm{R}_{2}\right)$ determine the chemical conversion inside the reactor (Eq. (2)). Despite qualitative insights into the reaction mechanism, reaction rates in literature are limited to the following irreversible and thermodynamically non-consistent expressions where $p_{\mathrm{CH}_{4}}$ and $p_{\mathrm{NH}_{3}}$ represent partial 
pressures of $\mathrm{CH}_{4}$ and $\mathrm{NH}_{3} \cdot{ }^{24-26}$

$$
\begin{array}{ll}
\mathrm{R}_{1}: & \mathrm{CH}_{4}+\mathrm{NH}_{3} \longrightarrow \mathrm{HCN}+3 \mathrm{H}_{2} \\
& r_{1}=\frac{7.8 \times 10^{18} \exp \left(\frac{-1950}{T}\right) p_{\mathrm{CH}_{4}} p_{\mathrm{NH}_{3}}^{1 / 2}}{\left(1+0.044 \exp \left(\frac{2390}{T}\right) p_{\mathrm{CH}_{4}} / p_{\mathrm{NH}_{3}}^{-1 / 2}\right)^{4}} \\
\mathrm{R}_{2}: \quad & \mathrm{NH}_{3} \longrightarrow \frac{3}{2} \mathrm{H}_{2}+\frac{1}{2} \mathrm{~N}_{2} \\
& r_{2}=\frac{4.9 \times 10^{18} \exp \left(\frac{-2130}{T}\right) p_{\mathrm{NH}_{3}}}{\left(1+0.044 \exp \left(\frac{2390}{T}\right) p_{\mathrm{CH}_{4}} / p_{\mathrm{NH}_{3}}^{-1 / 2}\right)^{3}}
\end{array}
$$

The volumetric source term $\sigma_{\alpha}$ is derived from the rates via catalyst surface $A_{s}$ to volume $V$ ratio and conversion to mass per production volume using the molar mass $\tilde{M}_{\alpha}$ and the Avogadro constant $N_{A} \cdot{ }^{26} \nu_{\alpha, i}$ denotes the stoichiometric coefficient of species $\alpha$ in reaction $r_{i}$

$$
\sigma_{\alpha}=\frac{A_{s}}{V} \frac{\tilde{M}_{\alpha}}{N_{A}} \sum_{i=1}^{N_{r}} \nu_{\alpha, i} r_{i}
$$

HCN synthesis reactors in the BMA process pathway are catalytic wall reactors. Therefore, $\sigma_{\alpha}(y):=0$ for all $y \in\left[0, y_{\max }\right)$ and $\sigma_{\alpha}(y) \neq 0$ for $y \equiv y_{\max }$.

Momentum transport in the fluid is described by the viscous stress tensor $\tau_{j k}$ that is defined by generalized Newton's law. ${ }^{27}$ Applying the boundary layer flow assumption to momentum transport reduces the stress tensor $\tau_{j k}$ to a single component $\tau^{*}=\eta \frac{\partial v_{z}}{\partial y}$ where $\eta$ is the viscosity of the gas mixture calculated using Wilke's mixing rule from pure component data. ${ }^{28-30}$ There are two causes for diffusive mass transport within the fluid: concentration gradients which are modeled with Maxwell-Stefan diffusion or Fick's law and diffusion caused by temperature gradients - the Soret effect. Despite the large temperature gradients in radial direction, mass at the reactor inlet, thermodiffusion is orders of magnitude smaller than mass transfer caused by concentration gradients and is therefore negligible. Furthermore, the high computational cost as well as instability due to the strong composition depen- 
dence render Maxwell-Stefan multicomponent diffusion unfeasible for five components in the gas mixture. Therefore, Wilke's effective diffusivity approach for a multicomponent mixture is applied and effective diffusivities are calculated from binary diffusion coefficients: ${ }^{29,31}$ $j_{y, \alpha}=-D_{\alpha, \text { eff }} \rho \frac{\partial w_{\alpha}}{\partial y}$.

The total heat flux is already replaced in Eq. (1e) by its enthalpy diffusion contribution as well as the conductive heat flux, therefore:

$$
q_{y}^{\text {tot }}=q_{y}^{(c)}+\sum_{\alpha=1}^{N_{c}} j_{y, \alpha} h_{\alpha}^{0}
$$

There exists also heat transfer due to concentration gradients (Dufour effect) which is, however, negligible compared to the transport phenomena considered here. Whereas the radiative flux is obtained from integration of the radiative transfer equation, conductive heat flux is modeled using Fourier's law where the thermal conductivity is obtained from kinetic theory of gases $q_{y}^{(c)}=-\lambda \frac{\partial T}{\partial y} \cdot{ }^{30}$

\section{Radiative Heat Transfer}

Radiative heat transfer is accounted for with an additional source term in the energy balance: $\nabla \mathbf{q}^{(r)}$ which is obtained via directional integration of the radiative transfer equation (RTE). In order to solve for the radiative heat flux vector, the radiative intensities are calculated using the discretized RTE (Eq. (1f)). The RTE is spatially, directionally and wavelength dependent and its solution requires emissivities of bounding surfaces as well as absorption coefficients for participating media. Scattering is of secondary importance compared to absorption and emission. ${ }^{21}$ The wall boundary condition of the RTE requires emissivities of the surface: Pure platinum catalyst $(\mathrm{Pt})$ has an emissivity of $\epsilon_{\mathrm{Pt}}=0.1$ and the wall material $\mathrm{Al}_{2} \mathrm{O}_{3}$ has an emissivity in the range $0.3<\epsilon_{\mathrm{Al}_{2} \mathrm{O}_{3}}<0.5$. Additionally, carbon deposits on the catalyst surface from adsorbed reaction intermediates and byproducts can hardly be excluded. Therefore an estimated surface emissivity of $\epsilon_{s}=0.5$ is justified. ${ }^{12}$ 
The derivation of absorption coefficients for gases is challenging because it occurs in discrete bands due to quantum effects. Whereas analytical data is used frequently e.g. in physics calculations of the atmosphere, there are only two substances of technical relevance that are widely investigated and readily accessible for reactor modeling: $\mathrm{CO}_{2}$ and $\mathrm{H}_{2} \mathrm{O} \cdot{ }^{13,32}$

Solution strategies for the RTE for gas mixtures are e.g. the multiple gray gases assumption or the weighted-sum-of-gray-gases approach - both of which are state-of-the-art in computational fluid dynamics codes. ${ }^{21}$ However, there are two drawbacks related to this strategy: the first is an increase in computational cost due to the necessity to solve several RTEs simultaneously and the second more severe drawback is the lack of abundant parameters for both methods. Another possibility to account for radiation without the necessity to solve multiple RTEs for different band widths is the use of mean absorption coefficients such as the Planck mean $\kappa_{P, \alpha}$ which is derivable from spectral absorption information of pure species. ${ }^{21}$ Eq. (5) is the definition of the Planck mean absorption coefficient of a single component $\alpha$ : spectral absorption data described by the spectral absorption coefficient $\kappa_{\eta, \alpha}$ is integrated over the entire wavenumber spectrum $\eta$

$$
\kappa_{P, \alpha}:=\frac{\int_{0}^{\infty} \kappa_{\eta, \alpha} I_{b \eta} \mathrm{d} \eta}{\int_{0}^{\infty} I_{b \eta} \mathrm{d} \eta}=\frac{1}{I_{b}} \int_{0}^{\infty} \kappa_{\eta, \alpha} I_{b \eta}
$$

Spectroscopic databases such as HITRAN or HITEMP are accessible via the HITRAN application programming interface (HAPI) to obtain absorption cross sections of pures that serve as a basis for the calculation of Planck mean absorption coefficients. ${ }^{33-36}$ HITRAN contains data at standard conditions: $T^{\ominus}=298 \mathrm{~K}$ and $p^{\ominus}=1013 \times 10^{2} \mathrm{~Pa}$. Temperature dependence of absorption spectra is taken into account via calculation of partition sums at different temperature levels and thus absorption coefficients for different temperatures are obtained according to Eq. (6).

$$
S_{i j}(T)=S_{i j}\left(T^{\ominus}\right) \frac{Q\left(T^{\ominus}\right)}{Q(T)} \frac{\exp \left(\frac{-h c E^{\prime \prime}}{k T}\right)}{\exp \left(\frac{-h c E^{\prime \prime}}{k T^{\ominus}}\right)} \frac{1-\exp \left(\frac{-h c \eta}{k T}\right)}{1-\exp \left(\frac{-h c \eta}{k T^{\ominus}}\right)}
$$


$S_{i j}(T)$ denotes the spectral line intensity, $Q(T)$ the partition sum, $E^{\prime \prime}$ the lower state energy, $h, c$ and $k$ represent Planck constant, speed of light and the Boltzmann constant. Planck mean absorption coefficients are derived in the unit $\mathrm{bar}^{-1} \mathrm{~m}^{-1}$. Substance dependence is taken into account via partial pressures of the species. Accordingly, all substances available in HITRAN are directly accessible in reactor simulations. To our knowledge, this is the first time that the calculation of the Planck mean absorption coefficient based on HITRAN is accessed directly for the simulation of a chemical reactor.

\section{Solution Strategy}

As explained at the beginning of the modeling section, the reactive channel flow and its underlying physical transport phenomena (Fig. 1 B) are described using a boundary layer formulation. The principle flow direction along the $z$-coordinate that is essential in the boundary layer flow assumption is exploited further for the solution of the system of PDEs given in Eq. (1) because it can be solved as a parabolic flow system using the method of lines: The PDEs are transformed into ordinary differential equations using finite volume discretization: at first, the PDEs are discretized manually in the transverse direction $y$. Subsequently, the resulting differential algebraic system (DAE) is integrated along the reactor coordinate $z$ using off-the-shelf integrators such as IDAS. ${ }^{37}$ The discretization scheme is illustrated in Fig. 2 and exemplified for the species mass balance for a non-wall element (Eq.(1b)) which is provided in the supporting information. The key to solving this strongly coupled DAE system is the discretization of transverse velocities in a staggered fashion: the discretized momentum balances in $z$-direction are used to solve for $v_{z}$ velocities whereas total continuity equations are used for determination of $v_{y}$. In this manner, there are $N_{y}+1$ transverse velocities among which $v_{y}(y=0)=v_{y}\left(y=y_{\max }\right)=0$. Therefore, $N_{y}-1$ total continuity equations are used for transverse velocity and one continuity balance is available for the pressure drop correction analogously to SIMPLE(R) algorithms. ${ }^{38}$ The influence of the discretization grid size on the solution precision is analyzed with a grid dependence study 

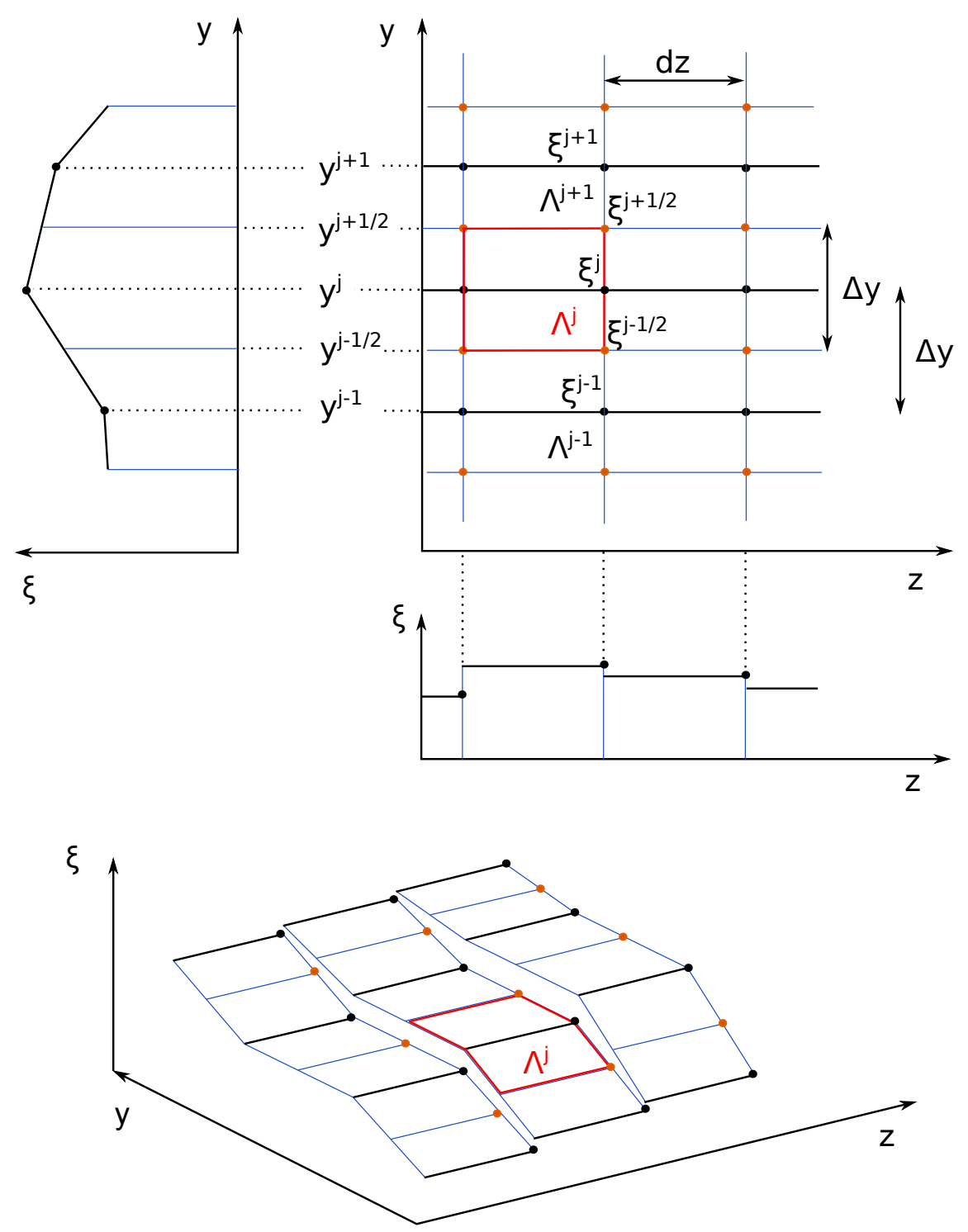

Figure 2: Discretization scheme in parabolic flow. A piecewise linear function is assumed in cross-flow direction $y$ and piecewise constant states are assumed in $z$. $\xi$ represents an arbitrary state. ${ }^{39}$

that is shown in Fig. 3 with the example of mass average HCN molar fractions at the outlet. ${ }^{40}$ A constant grid refinement ratio of 2 is used and the normalized grid spacing $\omega$ is defined as $\omega:=N_{\max } / N_{i}$. As a consequence, the point at a normalized grid spacing of 1 corresponds to e.g. 80 elements, at a grid spacing of 2 to 40 elements and so forth. Then, the data point at 0 - the Richardson extrapolate - corresponds to an infinitely fine mesh. The difference 


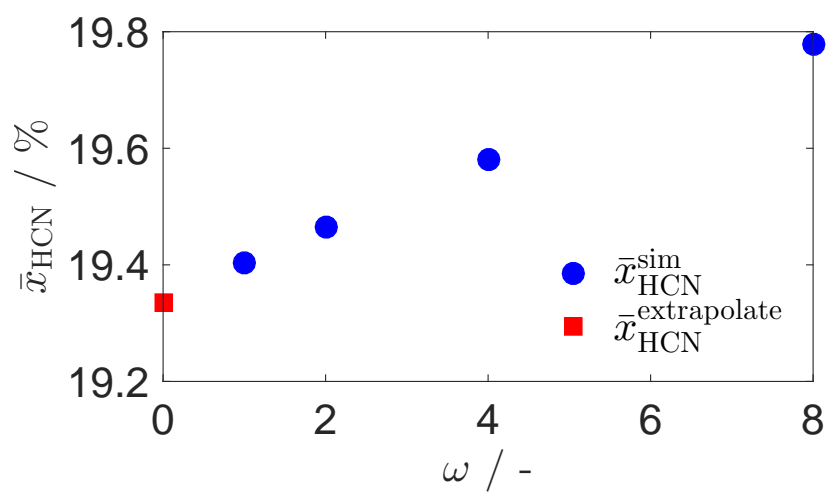

Figure 3: Grid dependence study for the reactor model. The deviation between Richardson extrapolate and coarsest grid is $2.3 \%$.

between Richardson extrapolate and the coarsest grid value is $2.3 \%$. Consequently, errors that originate from the mesh sizing are negligible.

\section{Results \& Discussion}

\section{Model Validation}

The reactor design and operating parameters for all simulations of the HCN synthesis reactor throughout this work as well as the simulation parameters are summarized in Table 1. Reactor length and width as well as inlet flow, composition and pressure are selected similar to industrial reactors. ${ }^{17} \mathrm{~A}$ preheated feed at $373 \mathrm{~K}$ is selected whereas the wall boundary temperature is assumed constant at $1500 \mathrm{~K}$. Without experimental insights into the catalyst surface structure, the catalyst surface area is approximated to equal the wall surface area. Space time is defined as $\tau:=V_{\text {ref }} / F_{\text {ref }}(z=0)$ and given as $0.8 \mathrm{~s}$. It is termed 'nominal' space time because it differs significantly from the residence time in the reactor $\tau_{R}$ that is illustrated below in Fig. 7. Concentration profiles as well as temperature and normalized reaction rates are shown in Fig. 4. Molar fractions of the reactant $\mathrm{CH}_{4}(\mathrm{~A})$ and the product HCN (B) illustrate reactant consumption and product formation near the catalytic reactor 
Table 1: Parameters for all reactor simulations used throughout this work.

\begin{tabular}{lllll}
\hline $\begin{array}{l}\text { simulation parameters } \\
\text { discretization elements in } y\end{array}$ & $N_{y}$ & $=50$ & - \\
discretization elements in $z$ & $N_{z}$ & $=200$ & - \\
\hline $\begin{array}{l}\text { design parameters } \\
\text { channel length }\end{array}$ & $L$ & & \\
channel width & $W$ & $=2$ & $\mathrm{~m}$ \\
\hline operating parameters & & & & \\
molar fraction $\mathrm{CH}_{4}$ at inlet & $x_{\mathrm{CH}_{4}}(z=0)$ & $=$ & & \\
molar fraction $\mathrm{NH}_{3}$ at inlet & $x_{\mathrm{NH}_{3}}(z=0)$ & $=$ & 0.44 & - \\
average inlet velocity in $z$ direction & $\bar{v}_{z}(z=0)$ & $=2.5$ & $\mathrm{~m} \mathrm{~s}^{-1}$ \\
nominal space time & $\tau_{\text {nom }}$ & $=0.8$ & $\mathrm{~s}$ \\
inlet temperature & $T(z=0)$ & $=373$ & $\mathrm{~K}$ \\
inlet pressure & $p(z=0)$ & $=1013$ & $\mathrm{hPa}$ \\
constant wall boundary temperature & $T_{w}$ & $=1500$ & $\mathrm{~K}$ \\
wall surface emissivity & $\epsilon_{s}$ & $=0.5$ & - \\
\hline
\end{tabular}

walls. At the same time, temperature is increasing with walls the boundaries reaching almost the wall temperature of $1500 \mathrm{~K}(\mathrm{C})$. Reaction rates are normalized with their maximum value because $r_{2}$ is five orders of magnitude smaller than $r_{1}(\mathrm{D})$. The side reaction $r_{2}$ is less endothermic than $r_{1}$ : whereas the latter requires more heat and thus exhibits a maximum at $z=7 \times 10^{-2} \mathrm{~m}$, the former rate $r_{2}$ decreases directly upon entering the reactor. Both reaction rates decrease exponentially due to quick consumption of the reactants $\mathrm{NH}_{3}$ and $\mathrm{CH}_{4}$ despite the sharp increase in temperature. In order to validate the reactor model, outlet molar fractions obtained from the rigorous model are compared with industrial plant data in Figure $5 .{ }^{17}$ Reactor outlet concentrations based on the reactor model match the plant data well but there appears to be a slight underestimation of the product yield that is obtained from the reactor model: Deviations in the reactor outlet concentrations may originate from an underestimation of the catalytic surface area and the reaction kinetic expressions that are used: the kinetic expressions assume a surface reaction rate limitation and neglect reverse reactions. ${ }^{25}$ Furthermore, product decay and polymerization side reactions are not contained in the kinetic model. ${ }^{41}$ A detailed understanding of mass transfer limitations is thus not possible using this kinetic model. ${ }^{42}$ Recent studies on reactor design for HCN synthesis in 


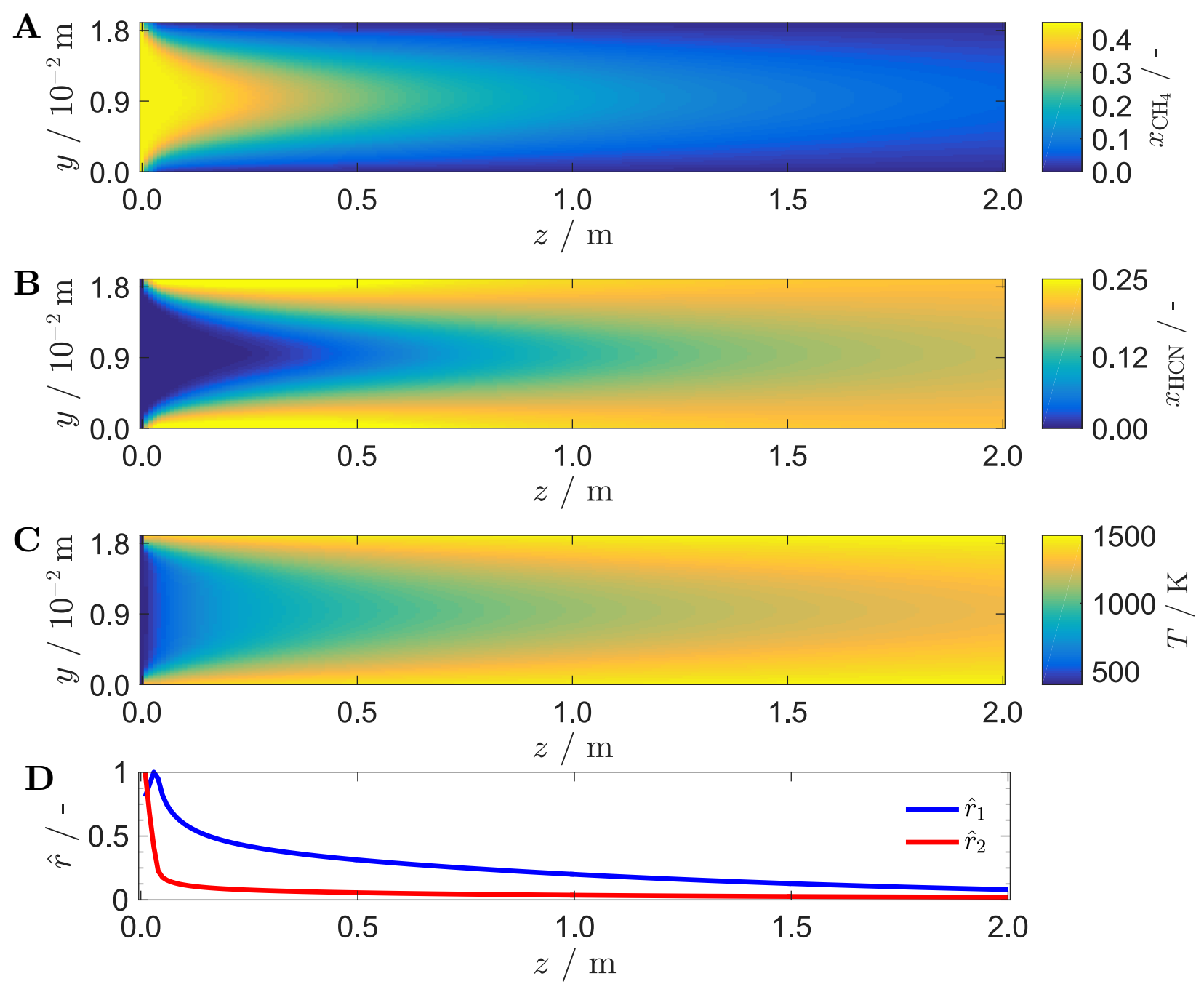

Figure 4: Spatially distributed reactant $x_{\mathrm{CH}_{4}}$ (A) and product $x_{\mathrm{HCN}}$ (B) molar fractions as well as temperature $(\mathrm{C})$ and normalized reaction rates (D) of the synthesis reaction $r_{1}$ (Eq. (2a)) and the side reaction $r_{2}$ (Eq. (2b)).

literature do not exist but a reaction rate limitation in the inlet region and a mass transfer limitation near the outlet were reported in the past. ${ }^{18}$ Modeling results match the model of Waletzko and Schmidt qualitatively well but the authors do not provide quantitative information in their article. ${ }^{43}$ Since the scope of this contribution is the analysis of fluid flow and heat transport phenomena, the kinetics that are available in literature are adequate. 


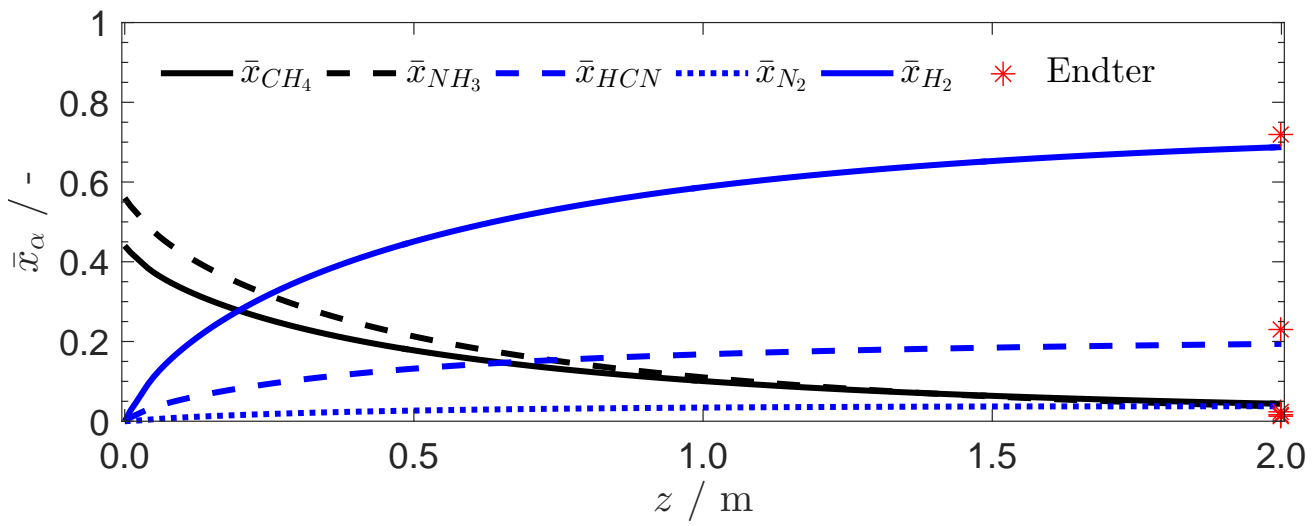

Figure 5: Cross-sectional average molar fractions $\bar{x}_{\alpha}$ versus reactor length of the reactor model compared with the reactor outlet composition of an industrial reactor. ${ }^{17}$

\section{Fluid-Dynamical Characteristics}

One may assume a forced flow regime in the reactor that is suitably described using HagenPoiseuille flow with averaged reactor properties. This assumption which is often valid for fixed-bed reactors is scrutinized in this section alongside with an investigation of the relevance of turbulent flow phenomena for the considered reactor. ${ }^{44}$

\section{Formation of Fluid-Dynamical Boundary Layers}

In a first step, the fluid-dynamical inlet behavior and establishment of a flow profile inside the reactor is investigated. This is illustrated with the axial velocity profiles under the assumption of an incompressible (Fig. 6, top) and a thermally dilatant flow (Fig. 6, bottom). In the incompressible flow scenario, the velocity profile remains constant along the reactor coordinate $z$ leading to residence times $\tau_{R}$ of $0.8 \mathrm{~s}$ and more (Fig. 7 (blue)). In the case of the thermally dilatant simulation the inlet velocity of $v_{u}=2.5 \mathrm{~m} \mathrm{~s}^{-1}$ increases strongly up to velocities in the range of $20.0 \mathrm{~m} \mathrm{~s}^{-1}$ in the center at the outlet of the reactor. A fully established velocity profile does not exist as it evolves under the influence of the temperature and composition changes along the reactor which is evident from the equation of state: pressure drop, temperature increase and a decline of the average molar mass due to the 

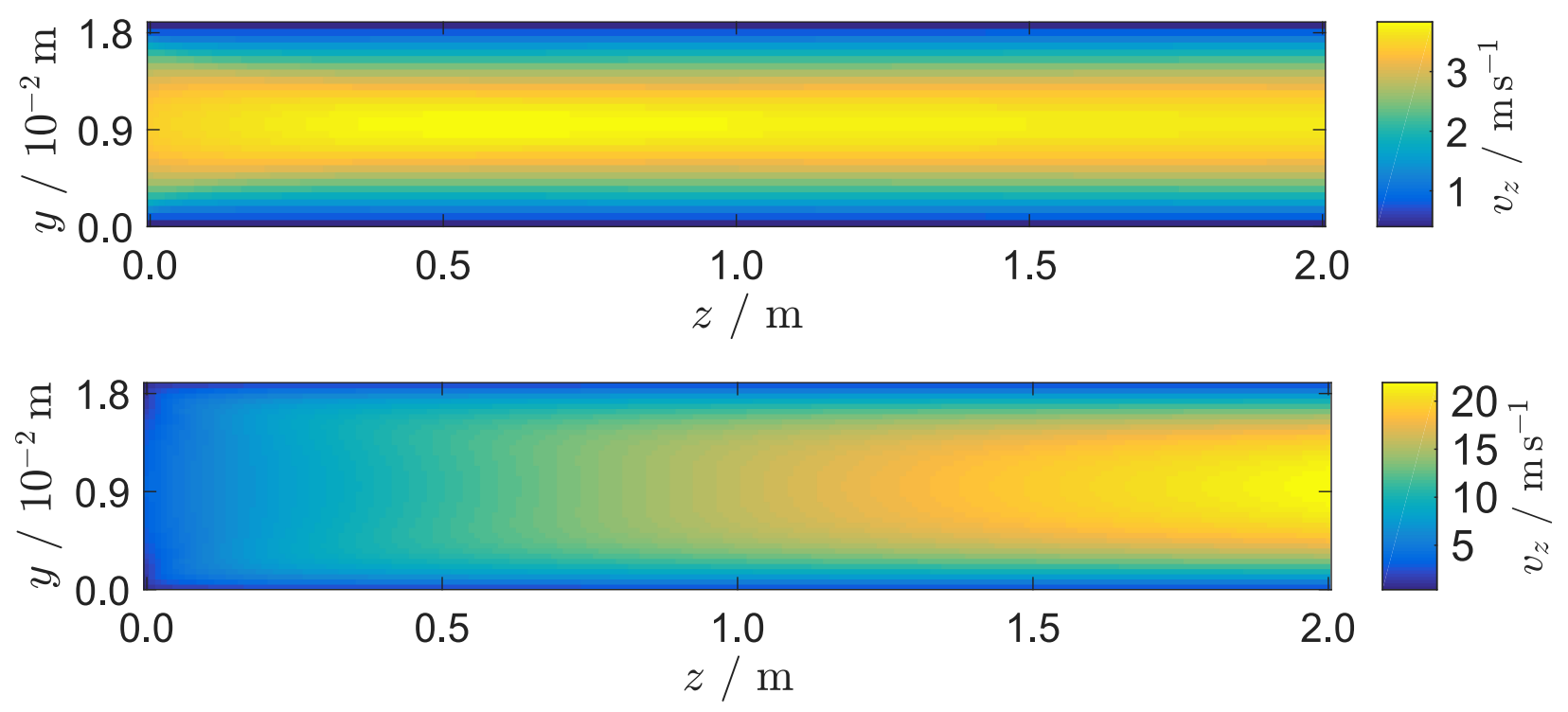

Figure 6: Magnitude of axial velocity component assuming incompressible flow (top) and a thermally dilatant flow (bottom).

formation of hydrogen in a stoichiometric ratio all lead to a sharp decrease in density.

This is relevant for estimation of residence times based on average velocities in the reactor

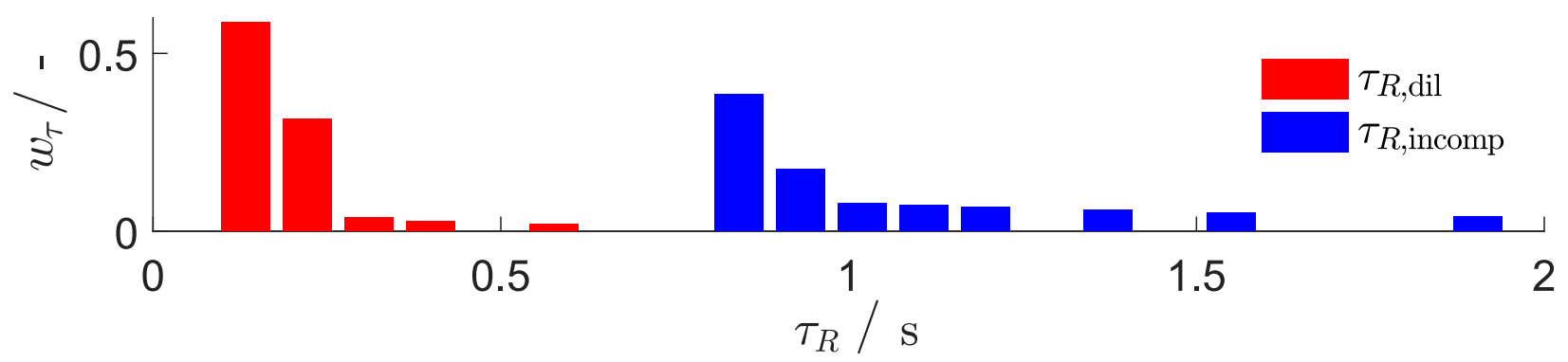

Figure 7: Total mass fraction $w_{\tau}$ versus residence time $\tau_{R}$ for incompressible (blue) and thermally dilatant (red) flow.

(Fig. 7). The total mass fraction is defined as the mass leaving the reactor at time $\tau_{R}$ versus the total mass entering the reactor at $\tau_{R}=0: w_{\tau}:=M\left(\tau_{R}, z=L\right) / M\left(\tau_{R}=0, z=0\right)$. The peak of the residence time distribution $\tau_{R}$ of the thermally dilatant flow is 5 times lower compared to incompressible flow. Residence times are crucial for reactor design and an inappropriate simplification such as incompressibility may lead to inadequate dimensioning of the reactor. The decline of density along the reactor coordinate $z$ exists also in SMR reactors where similar conditions exist. 


\section{Turbulence Analysis}

Despite the strong increase in velocity, the flow pattern is still adequately described as laminar since the cross-sectional averaged Reynolds number remains below the critical value of $\mathrm{Re}_{\text {crit }} \approx 1200$ for parallel plate internal flow (Fig. 8 bottom). ${ }^{45}$

Considering the spatially distributed Reynolds numbers in the top section of Fig. 8, Re
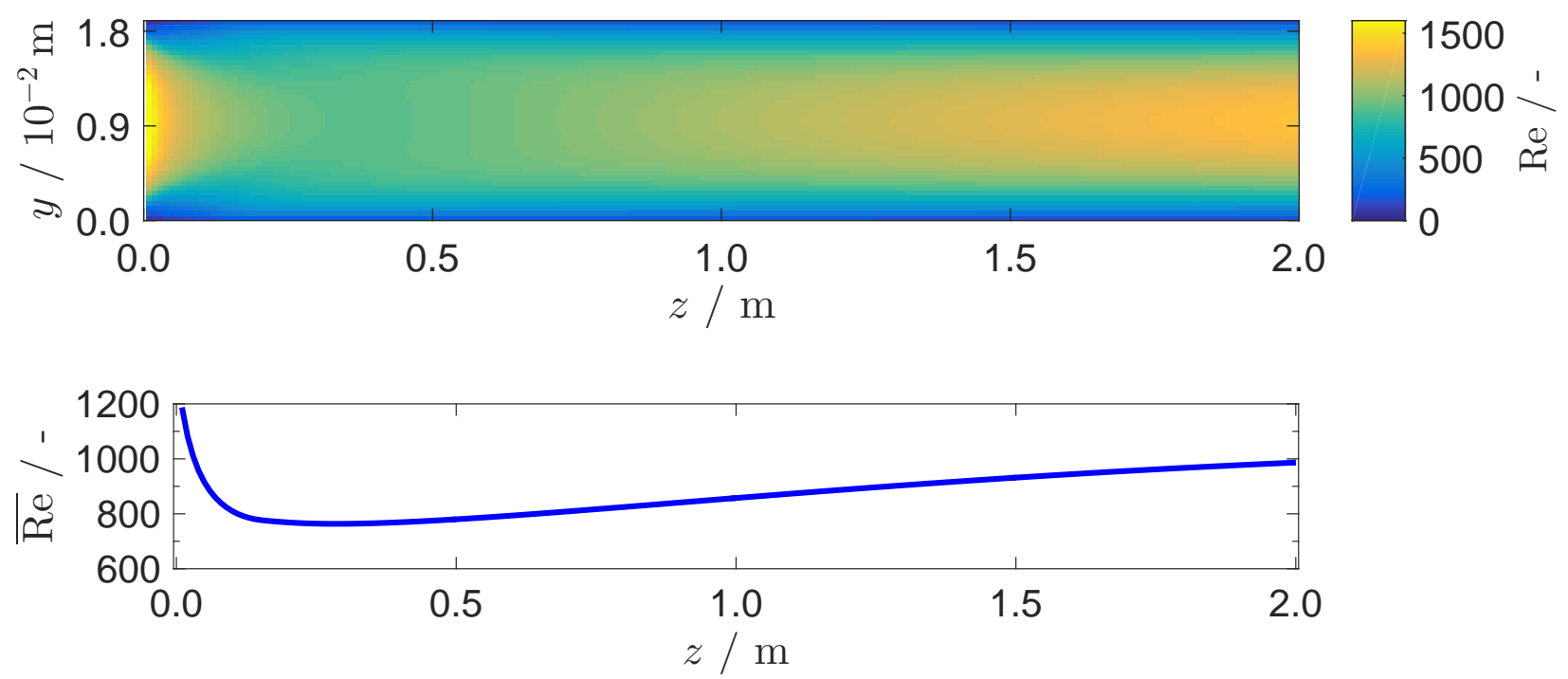

Figure 8: Spatially distributed Re number (top) and cross-sectional averaged Reynolds values versus reactor length $\overline{\mathrm{Re}}$ (bottom).

values in the cold inlet region of the reactor are in the turbulent transition regime but drop sharply within the first $15 \mathrm{~cm}$ due to the increase in temperature: the increase in velocities is smaller than the increase in gas viscosities leading to an overall decline of Re values. The increase in Re towards the outlet of the reactor originates from two reasons: hydrogen is formed as a stoichiometric byproduct of the synthesis which has a lower viscosity than the reactants and the velocity is increased continuously along the reactor coordinate whereas the temperature and thus overall viscosity increase is less significant compared to the reactor inlet region. Overall, near-critical Re values exist close to the inlet and towards the reactor outlet. The existence and impact of turbulence on the flow pattern is not directly evident from the model but is estimated with wall $\mathrm{y}^{+}$values in Fig. 9. The wall $\mathrm{y}^{+}$analysis reveals that out of the two potentially turbulent flow regions of the reactor - the inlet and near 
outlet regions - the $\mathrm{y}^{+}$values exceed the critical value of 50 solely at $z \leq 1 \times 10^{-1} \mathrm{~m}$ but not towards the outlet of the reactor. ${ }^{46}$ The overall impact of turbulence on the reactor behavior is thus of less importance.

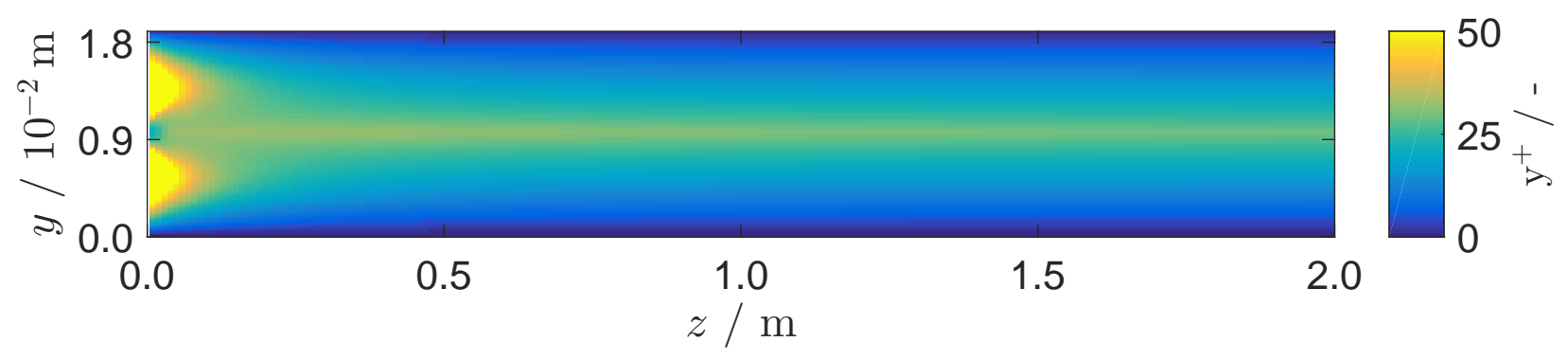

Figure 9: Wall $\mathrm{y}^{+}$in the reactor.

\section{Impact of Buoyancy Forces}

Buoyancy may play a role due to the upright orientation of the reactor. It is evident that advection dominates flow due to buoyancy once the synthesis gas mixture attains the wall temperature. However, the identification of the flow regime near the inlet region is challenging and due to the large temperature gradients either forced convection, mixed or free flow may dominate. An estimate is obtained with the ratio of Grashoff number Gr versus Re squared: $\mathrm{Gr} / \operatorname{Re}^{2} \cdot{ }^{47}$ Values below 0.3 are considered forced convection and ratios beyond 16 free convection. In between lies the mixed flow regime.

This ratio is calculated for three selected conditions near the reactor inlet where the impact of buoyancy forces is expected to reach its maximum and the results are illustrated in Fig. 10: the first sample point is located close to the wall at $v_{z}^{\mathrm{I}}(z=0.10 \mathrm{~m}, y=0.001 \mathrm{~m})=$ $0.5 \mathrm{~m} \mathrm{~s}^{-1}$, the second sample point is located at the inlet and center of the cross section $v_{z}^{\mathrm{II}}(z=0.00 \mathrm{~m}, y=0.01 \mathrm{~m})=2.5 \mathrm{~m} \mathrm{~s}^{-1}$ and the last sample point is located $0.5 \mathrm{~m}$ into the reactor at the center of the cross section at $v_{z}^{\mathrm{III}}(z=0.50 \mathrm{~m}, y=0.01 \mathrm{~m})=5.0 \mathrm{~m} \mathrm{~s}^{-1}$. The ratio of $\mathrm{Gr} / \mathrm{Re}^{2}$ decreases with increasing temperatures due to the reduced temperature difference with the wall which is the driving force for buoyancy. Additionally, higher temperatures result in higher denominators and thus smaller ratios. 
The rigorous modeling approach provides straight access to all terms in the momentum

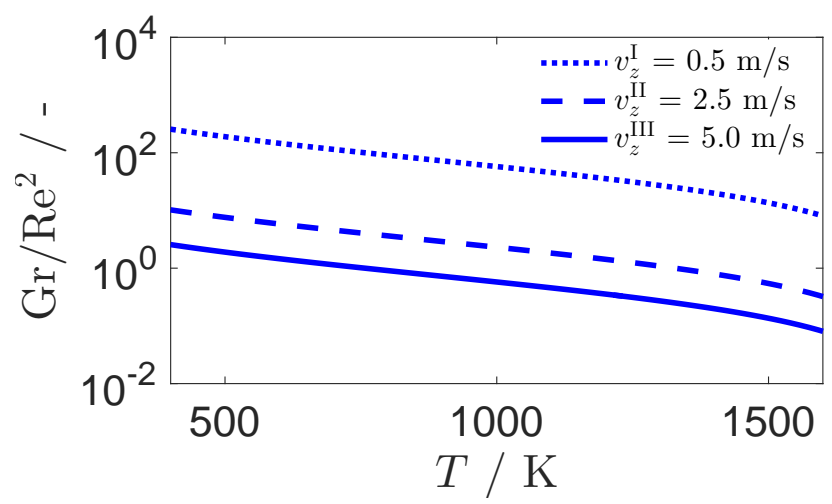

Figure 10: $\mathrm{Gr} / \mathrm{Re}^{2}$ ratio for three sampling points in the reactor with $v_{z}^{\mathrm{I}}$ (dotted line), $v_{z}^{\mathrm{II}}$ (dashed line) and $v_{z}^{\mathrm{III}}$ (full line).

balance. Consequently, a model-based buoyancy fraction is calculated as buoyancy term versus convective term of Eq. (1c). Fig. 11 illustrates the simulation results in two dimensions using a logarithmic color scale. The flow regimes that were estimated in Fig. 10 are

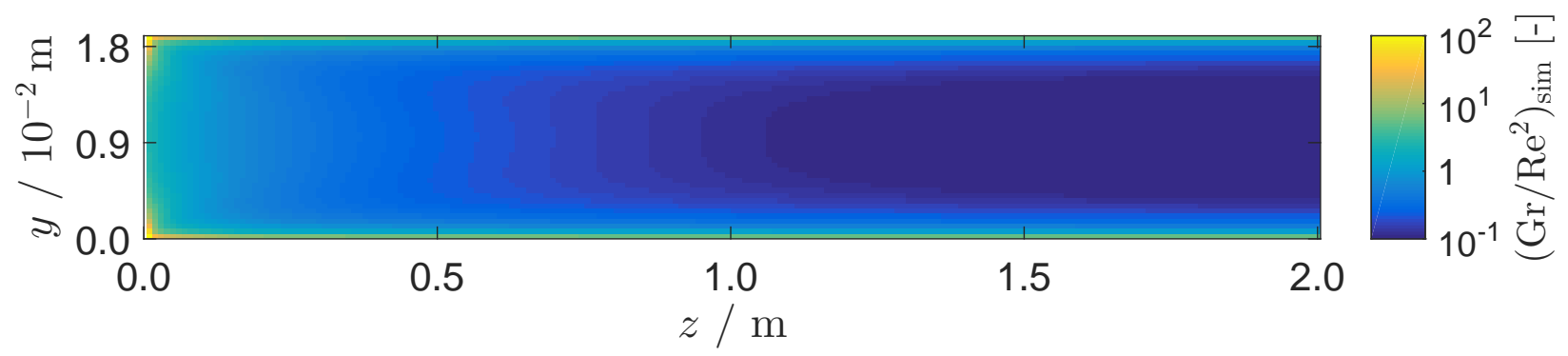

Figure 11: $\mathrm{Gr} / \mathrm{Re}^{2}$ ratio obtained from the two-dimensional reactor model: near-wall and near-entry regions exhibit mixed and free flow regimes.

confirmed well: Mixed flow where both forced convection and free flow are relevant exist close to the reactor walls and near the reactor inlet. The two regions that are closest to the walls with $y$ values below $1 \mathrm{~mm}$ and above $1.8 \mathrm{~mm}$ are even in the pure free flow regime. The center of the reactor is in the mixed regime up to $z=0.36 \mathrm{~m}$ where it enters the forced flow regime. Overall, the largest part of the reactor is dominated by forced convection but buoyancy is significant in the inlet and near wall region. 


\section{Heat Transfer Characteristics}

Understanding heat transfer characteristics of high-temperature reactors is of major importance because of their high energy cost. Identification of the key heat transport phenomena enables improvements in the performance, efficiency and economics of a process. The section is structured into an analysis of the energy balance followed by the calculation of parameters that are required for effective radiative heat transfer modeling and concluded with an analysis of the importance of the three modes of heat transfer for the example of HCN synthesis.

\section{Energy Balance Analysis}

In order to identify the relevant heat transfer modes in the reactor, all nine contributing terms $\chi_{i}$ with $i \in[1,9]$ in Eq. (1e) are integrated and illustrated in a logarithmic graph in Fig. 12. The simulation results are shown for a constant radiative absorption coefficient $\kappa=4.0 \mathrm{bar}^{-1} \mathrm{~m}^{-1}$ which is an approximate value for a 50:50 mixture of $\mathrm{CH}_{4}: \mathrm{NH}_{3}$ and read from Hottel charts. ${ }^{48}$ The buoyancy term $\left(\chi_{9}\right)$ is in the order of $10^{-5}$ and therefore not visualized in Fig. 12. All red curves denote terms with magnitudes larger than $10^{3}$ while the blue curves denote all terms of smaller magnitudes. Enthalpy diffusion $\left(\chi_{5}\right)$, convection in $y$ direction $\left(\chi_{6}\right)$, pressure work $\left(\chi_{7}\right)$ as well as dissipation losses $\left(\chi_{8}\right)$ are of minor magnitudes compared to the other terms in the energy balance. This is well in agreement with standard literature where these terms are often neglected a priori in the energy balance of a reactive flow model. ${ }^{49}$ The red lines in Fig. 12 represent conduction in $y$ direction $\left(\chi_{1}\right)$, heat of reaction $\left(\chi_{2}\right)$, convection in $z$ direction $\left(\chi_{3}\right)$ and radiative heat transfer in $y$ direction $\left(\chi_{4}\right)$. All four terms have similar orders of magnitude but there is a strong dependence of term $\chi_{4}$ on the radiative absorption parameter $\kappa$ that is decisive for the radiative heat transfer calculation. The strongly composition and temperature dependent radiative absorption coefficient is the sole parameter within the radiative transfer equation (Eq. (1f)) and is analyzed in the next section. 


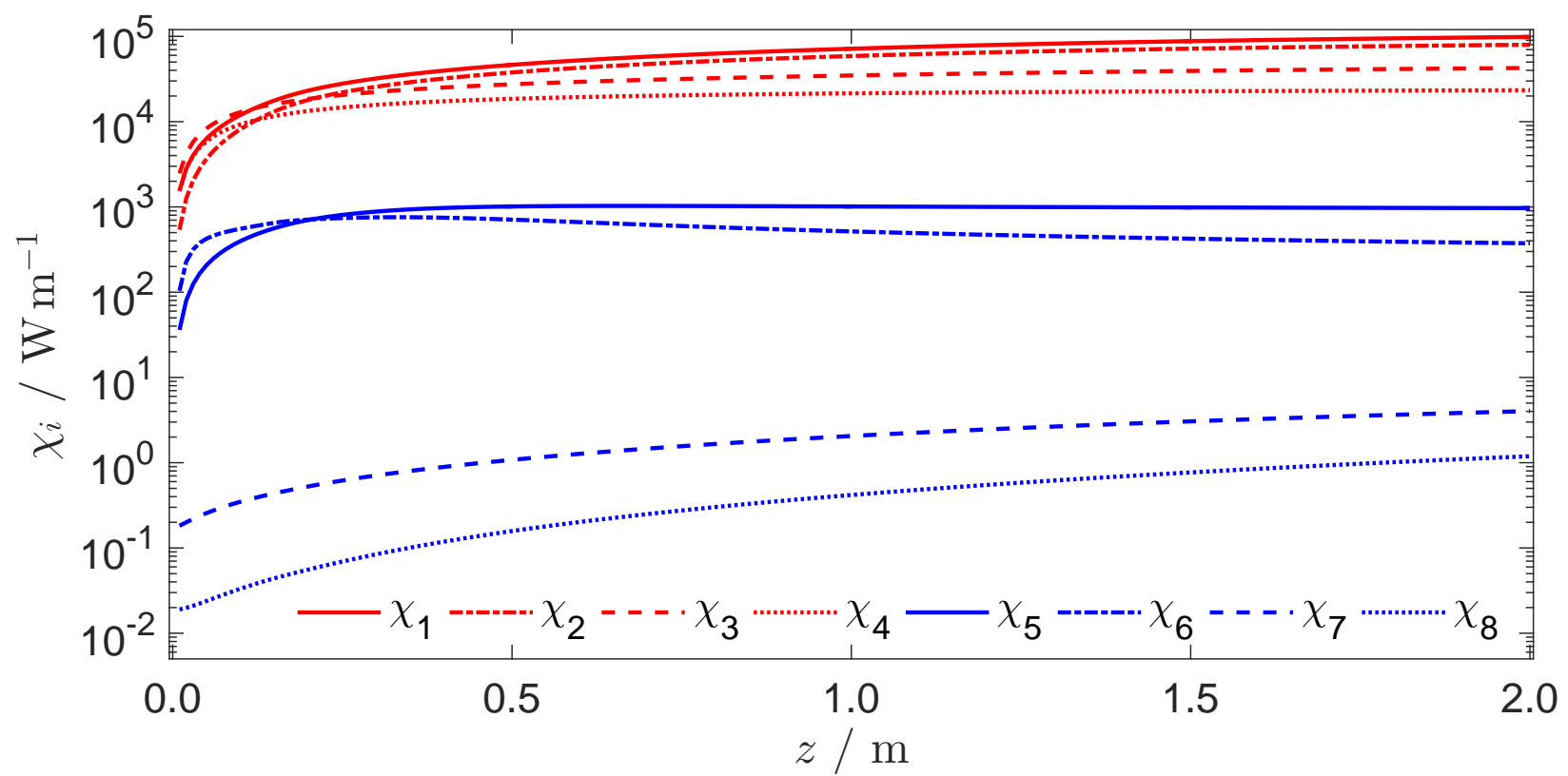

Figure 12: Integration of the energy balance in separate terms $\left(\chi_{i}\right)$ split into terms of major importance (red curves) and negligible contributions to the energy balance (blue curves). Lines represent: $\chi_{1} \ldots$ conduction in $y$ direction, $\chi_{2} \ldots$ heat of reaction, $\chi_{3} \ldots$ convection in $z$ direction, $\chi_{4} \ldots$ radiative heat transfer in $y$ direction, $\chi_{5} \ldots$ enthalpy diffusion, $\chi_{6} \ldots$ convection in $y$ direction, $\chi_{7} \ldots$ pressure loss term, $\chi_{8} \ldots$ dissipation (comp. Eq. (1e)).

\section{Absorption Coefficient Modeling}

Whereas the peak radiation intensity of a blackbody shifts towards higher wave numbers with increasing temperatures as described by Wien's and Planck's laws, the peaks of the absorption spectra of gases remain at their positions since they correspond to discrete rotational and vibrational energy transitions. ${ }^{21}$ On the contrary, magnitudes of their absorption peaks decrease slightly due to peak broadening originating from more energy levels becoming accessible to the molecule and thus an exponential increase in the partition sum with increasing temperatures. The effects of the accessibility of the higher energy levels on quantitative radiative heat transfer calculations were assumed to be significant in the past. ${ }^{34}$ More recently, however, new data suggest that higher energy levels are negligible for quantitative radiation calculations. ${ }^{50}$ For this reason, the application of HITRAN spectroscopic data that is used throughout this work is justified at temperatures above $1000 \mathrm{~K}$ even though these temperatures exceed the recommended temperature range for spectroscopic and analytic 
purposes of the HITRAN database.

Planck mean values for $\mathrm{CH}_{4}, \mathrm{NH}_{3}$ and $\mathrm{HCN}$ (blue) are shown in Fig. 13 and compared with values of $\mathrm{CO}_{2}$ and $\mathrm{H}_{2} \mathrm{O}$ (red) that dominate radiative heat transfer of gases in furnaces. Nitrogen and hydrogen are in their elemental state and do not contribute significantly to radiative heat transfer. The Planck mean absorption coefficients of $\mathrm{CH}_{4}, \mathrm{NH}_{3}, \mathrm{CO}_{2}$ and $\mathrm{H}_{2} \mathrm{O}$

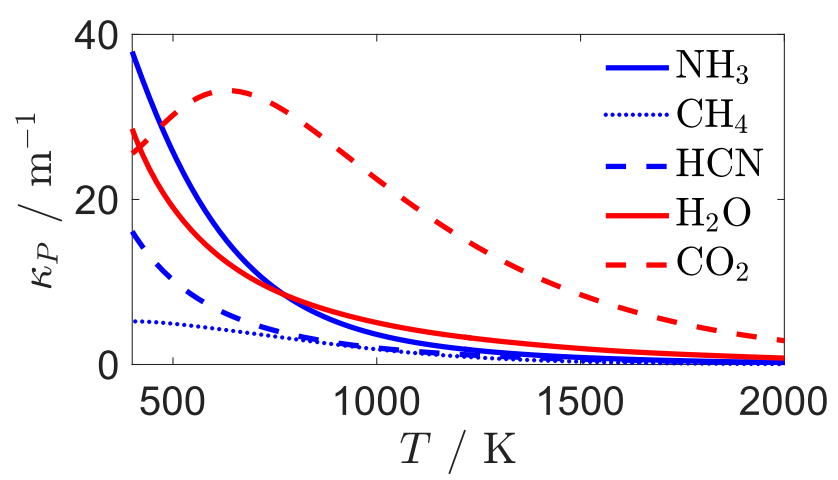

Figure 13: $\kappa_{P}$ of the relevant species of $\mathrm{HCN}$ synthesis $\mathrm{CH}_{4}, \mathrm{HCN}, \mathrm{NH}_{3}$ compared with $\mathrm{CO}_{2}$ and $\mathrm{H}_{2} \mathrm{O}$.

match literature data well. ${ }^{50}$ All $\kappa_{P}$ decrease with temperature as expected based on Wien's law: the maximum of radiation intensity lies in the absorption region of the gases at lower temperatures. The molecules of $\mathrm{NH}_{3}$ and $\mathrm{H}_{2} \mathrm{O}$ have similar symmetries and thus absorb and emit comparable quantities of electromagnetic radiation. $\mathrm{CO}_{2}$ absorbs significantly more than all other species and high $\kappa_{P}$ values at temperatures up to $2000 \mathrm{~K}$. HCN absorbs in similar magnitudes as $\mathrm{CH}_{4}$. Overall, it is therefore expected that radiative heat transfer is significant in the inlet region where absorption coefficients and temperature gradients are high and ammonia with its strong radiative absorption is abundant. Towards the center and outlet of the reactor the contribution of radiative heat transfer is expected to diminish as the synthesis gas mixture heats up and lower-absorbing $\mathrm{HCN}$ and $\mathrm{H}_{2}$ are synthesized from $\mathrm{CH}_{4}$ and $\mathrm{NH}_{3}$.

To demonstrate the impact of the radiation model and of the parameter $\kappa_{P}$, average temperature levels and absorption coefficients along the reactor coordinate $z$ are shown in Fig. 14 . Reactor simulations with approximated Planck mean absorption coefficients - a constant $\kappa_{P}$ 
of $4 \mathrm{~m}^{-1}$ in the entire reactor (scenario I) and a composition dependent but temperature independent $\kappa_{P}$ of $4 \mathrm{bar}^{-1} \mathrm{~m}^{-1}$ (scenario II) - in blue and blue dashed lines respectively are compared with Planck mean absorption coefficients with correct temperature and species dependence (scenario III). In addition to that, the average temperature profile in the reactor is provided if no radiative heat transfer is taken into account (scenario IV). Fig. 14 (left) demonstrates the importance of taking radiative heat transfer into account: the fluid inside the reactor heats up significantly slower compared to the models that take radiation into account achieving an outlet temperature of $1120 \mathrm{~K}$ compared to $1360 \mathrm{~K}$ for the correct species and temperature dependent model (III). Comparing the constant absorption coef-
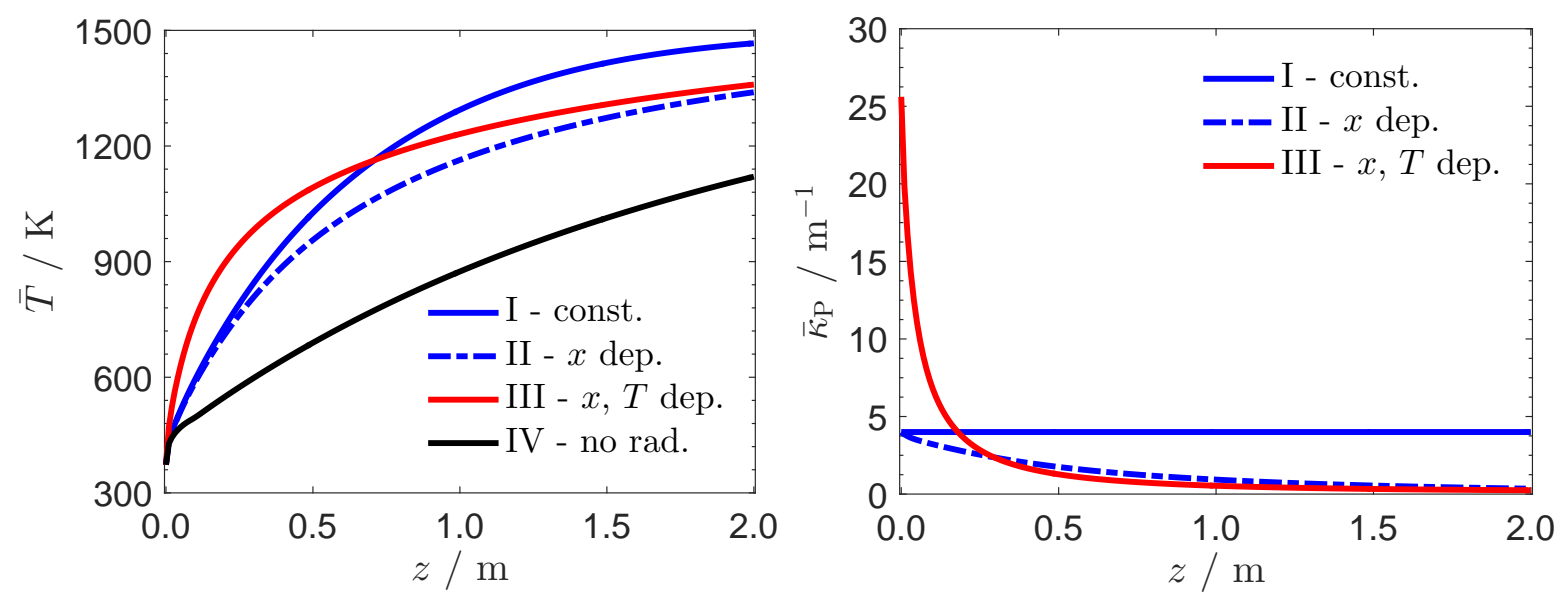

Figure 14: Cross-sectional average temperature (left) and average Planck mean absorption coefficient $\kappa_{P}$ (right) along the reactor coordinate $z$ for four radiation model scenarios: 'I - const.' is a simulation with constant $\kappa_{P}$ of $4 \mathrm{~m}^{-1}$ (blue line), 'II - $x$ dep.' with correct species but no temperature dependence assuming $\kappa_{P}=4$ bar $^{-1} \mathrm{~m}^{-1}$ for $\mathrm{NH}_{3}$ and $\mathrm{CH}_{4}($ blue dashed line), 'III - $x, T$ dep.' illustrates results with correct temperature and composition dependent $\kappa_{P}$ (red line) and 'IV - no rad.' illustrates results without taking radiative heat transfer into account (black line).

ficient approximation (I) and the correct species and temperature dependent model (III) in Fig. 14 (right), the constant coefficient approximation (I) underestimates radiative absorption near the inlet of the reactor and overestimates $\kappa_{P}$ above $z=0.23 \mathrm{~m}$ which is clearly visible in the temperature graph on the left where the temperature of (I) increases more slowly than (III) at the inlet but keeps increasing until the reactor outlet. Approximating the absorption coefficient species dependently with a value of $4 \mathrm{bar}^{-1} \mathrm{~m}^{-1}$ for $\mathrm{CH}_{4}$ and $\mathrm{NH}_{3}$ 
illustrated by scenario (II) also underestimates radiative absorption near the inlet region but leads to slightly higher overall absorption coefficients compared to the correct substrate and temperature dependent scenario (III) beyond $z=0.28 \mathrm{~m}$. The correct species and temperature dependent model (III) exhibits the highest absorption coefficient values near the reactor inlet. Consequently, the highest temperature slope in Fig. 14 (left) out of all scenarios occurs before $z=0.23 \mathrm{~m}$. Caused by the sharp decline of $\kappa_{P}$ in model (III), however, this model drops below both (I) and (II) after $z=0.23 \mathrm{~m}$ leading to the most shallow temperature slope of all three scenarios.

Interestingly, the second modeling scenario (II) results in similar outlet temperatures as model (III) due to the switch from under- to overestimation of $\kappa_{P}$. Overall, the detailed physical model helps in understanding the heat-up at the inlet region and prediction of the temperature field along the reactor. This information is applied in the following step for the identification of the key heat transfer phenomena.

\section{Identification of Key Heat Transfer Mechanisms}

The previous section illustrated the importance of radiation and an adequate physical model of radiative heat transfer in order to gain insights into heat transfer phenomena of hightemperature reactors. The importance and relevance of the three modes of heat transfer in the transverse direction $y$ is addressed in this section. Two dimensionless numbers indicate the relevance of radiative heat transfer compared to conduction and convection: the Boltzmann number Bo and the Planck number $\mathrm{N}$ representing a ratio of convective-to-radiative and a ratio of conductive-to-radiative heat transfer:

$$
\text { Bo }:=\frac{\rho c_{p} v_{\infty}}{n^{2} \sigma T_{\infty}^{3}} \quad \mathrm{~N}:=\frac{\lambda \kappa}{4 n^{2} \sigma T_{\infty}^{3}}
$$

where $n$, and $\sigma$ represent the refractive index and the Stefan-Boltzmann constant whereas $v_{\infty}$ and $T_{\infty}$ denote the velocity and temperature in the continuum adjacent to the boundary 
layer.

The analysis of the energy balance that is illustrated in Fig. 12 showed that heat transfer via convection in $y$ direction is negligible compared to the other heat transfer mechanisms. The Bo number is thus expected to be below one. Estimations of the importance of cross-flow

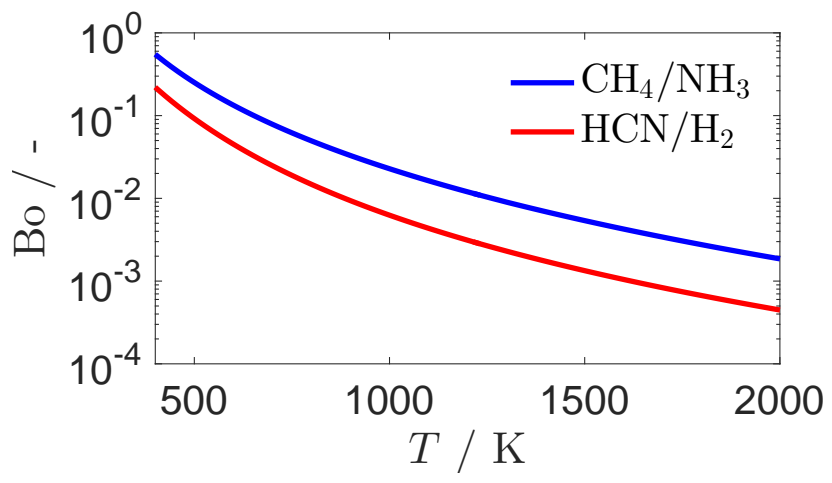

Figure 15: Bo versus $T_{\infty}\left(50: 50 \mathrm{CH}_{4}: \mathrm{NH}_{3}\right.$ in blue and 25:75 $\mathrm{HCN}: \mathrm{H}_{2}$ in red

convection over radiation are illustrated in Fig. 15 where the Boltzmann number is shown on a logarithmic scale versus temperature. The graph illustrates Boltzmann number values for two characteristic gas mixtures - pure reactants and pure products - and confirms that all Bo values are below one even if maximum transverse velocities $v_{y}$ of $0.5 \mathrm{~m} \mathrm{~s}^{-1}$ are assumed: Convection is indeed negligible for heat transfer in $y$-direction.

The conduction-to-radiation or Planck number is calculated with temperature and composition dependent radiative absorption coefficients and illustrated in Fig. 16 in a semilogarithmic graph. For both sample compositions - reactants and products - N remains well below 1 and again decreases strongly with temperature due to $T_{\infty}^{3}$ in the denominator and the product of thermal conductivity and radiative absorption coefficient remaining approximately constant indicating that conduction is negligible compared to radiation. For the reactor model, a conduction-to-radiation ratio $\mathrm{N}_{\text {sim }}$ is defined analogously to the buoyancy ratio above: $\mathrm{N}_{\text {sim }}:=q_{y}^{(c)} / q_{y}^{(r)}$. The results of the spatially distributed Planck number are shown in Fig. 17 (top). The dark blue region at the center and inlet of the reactor indicates that radiative heat transfer is the dominant mode of heat transfer in this region whereas the 


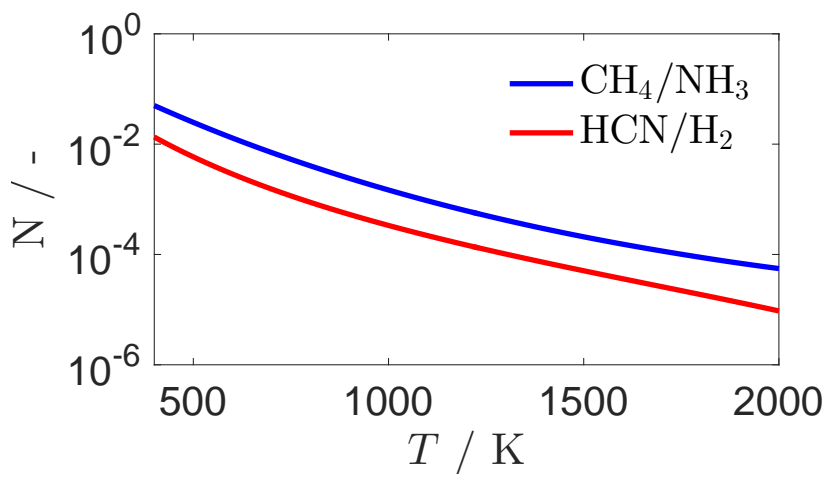

Figure 16: $\mathrm{N}$ versus $T_{\infty}\left(50: 50 \mathrm{CH}_{4}: \mathrm{NH}_{3}\right.$ in blue and 25:75 $\mathrm{HCN}: \mathrm{H}_{2}$ in red

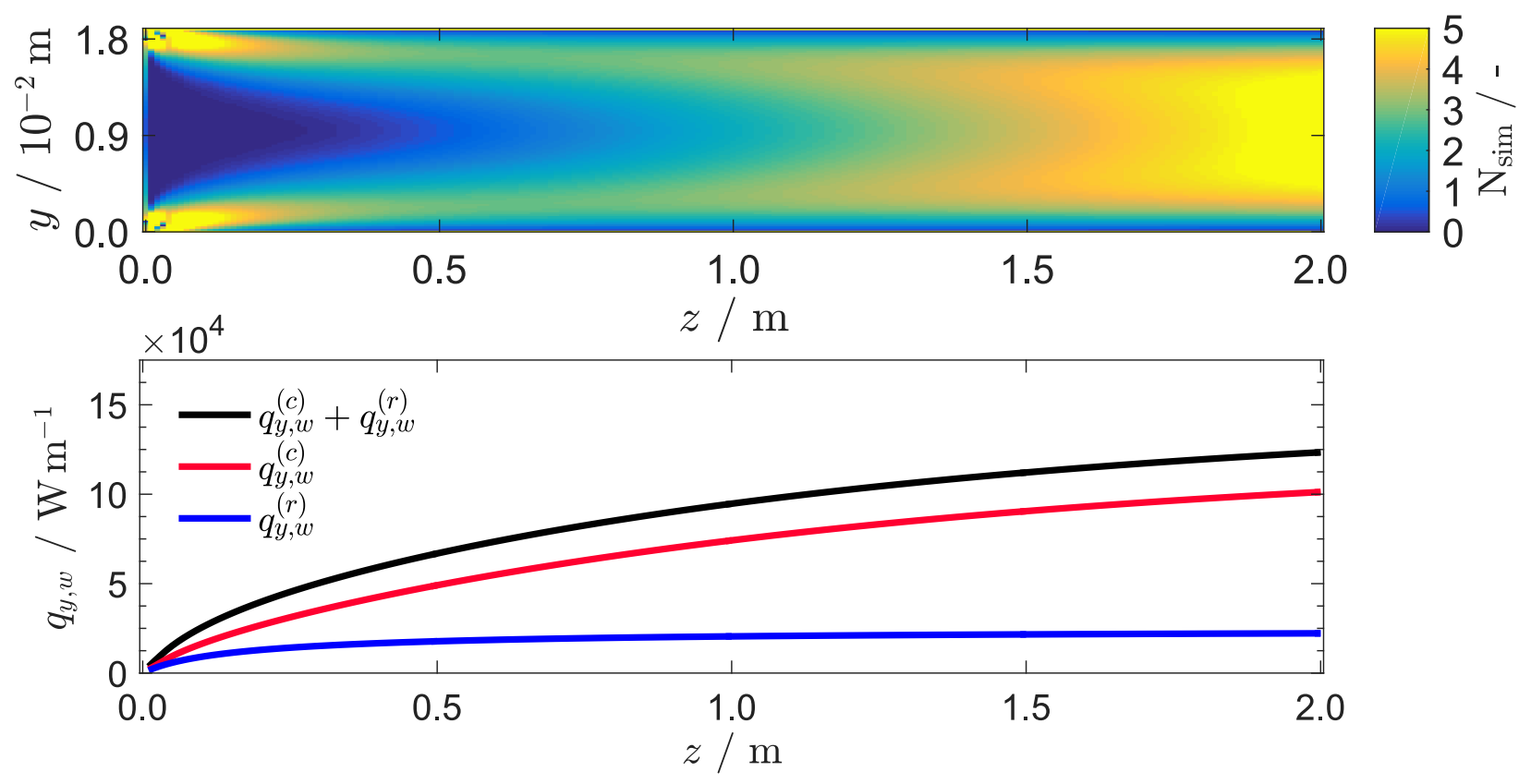

Figure 17: Spatial distribution of the Planck number $\mathrm{N}_{\text {sim }}$ (top) and cumulative wall heat fluxes via conduction (red) and radiation (blue) into the fluid (bottom). The sum of conductive and radiative wall heat fluxes is illustrated with the black line.

conductive heat flux clearly dominates the near wall section providing heat to the chemical reaction and in particular in the inlet region where the thermal boundary layer starts to form (until $z=0.15 \mathrm{~m}$ ). The last section of the reactor where boundary layers are fully developed (beyond $1.5 \mathrm{~m}$ ) is dominated by conductive heat transfer. The cumulative wall heat fluxes are displayed in Fig. 17 (bottom). As shown in the top part, radiation contributes significantly to the heat uptake of the fluid especially near the inlet of the reactor until $z=0.5 \mathrm{~m}$. 
Overall, the main heat transfer mechanism is conduction with $81.9 \%$ of the total heat transferred into the fluid but radiative heat transfer contributes significantly accounting for the remaining $18.1 \%$.

These findings seem to contradict the Planck number results in Fig. 17 that showed a clear dominance of radiative heat transfer in the entire temperature range. The reasons for that are that radiation propagates to much higher extents through the gas compared to conduction as indicated by N. The low optical thickness of the gas mixture minimizes resistance to radiative heat transfer through the fluid but at the same time it is mostly transparent to radiation. Heat uptake of the gas mixture due to radiative heat transfer is therefore slow. Consequently, both results complement each other. An additional aspect is the reactor geometry that is considered in this contribution. The total width of the channel is $1.9 \times 10^{-2} \mathrm{~m}$. Within the first few millimeters of the boundary layer that forms in the inlet region of the reactor conductive heat transfer into the gas dominates whereas radiation becomes significant after roughly $5 \times 10^{-3} \mathrm{~m}$ as was shown recently. ${ }^{39}$

In summary, heat transfer in $z$-direction of the synthesis compartments is dominated by convection due to high flow velocities. For the transverse direction $y$, however, radiation contributes significantly to the heat uptake of the fluid near the inlet whereas conduction dominates heat transfer within the boundary layers in the near-wall regions where the endothermic chemical reactions occur as well as towards the outlet of the reactor.

\section{Conclusion}

Key transport phenomena that govern fluid flow and heat transfer are identified in this contribution using an industrially relevant example - the synthesis of $\mathrm{HCN}$ - and a rigorous modeling approach. The model is successfully validated with industrial data and compared with literature. There exist pronounced changes in temperature, mixture molar mass and pressure making the flow thermally dilatant. Furthermore, the flow is within the laminar 
regime with negligible influence of turbulence but considerable effects of buoyancy near walls and near the inlet of the reactor. Subsequently, the energy balance is analyzed with particular emphasis on heat transfer modeling: four terms dominate the energy balance in terms of magnitudes: convective heat transfer along the reactor $(z)$, the enthalpy changes due to the chemical reaction and the energy uptake of the reactor via conductive and radiative heat transfer in transverse $(y)$ direction. Modeling the radiative absorption coefficients is emphasized and the effect of false modeling assumptions are illustrated: the reactor model contains species and temperature dependent absorption coefficients that are derived using data of the spectroscopic database HITRAN. Neglecting this temperature and species dependence or radiative heat transfer as a whole leads to drastically different reactor temperature profiles and outlet temperatures. At last, prevalence of the heat transfer mechanisms is analyzed: convection dominates heat transfer in the principle flow direction $z$ but is insignificant for the energy uptake in transverse direction $y$ as suggested by dimensionless numbers. There, both radiation and conduction are equally important accounting for $18.1 \%$ and $81.9 \%$ of the total heat transferred into the fluid: radiation is particularly significant to heat up the bulk fluid near the inlet of the reactor where thermal boundary layers are beginning to form. Conduction on the other hand provides the energy for the endothermic chemical reaction at the catalytic wall and prevails once the boundary layers are fully established. In order to extend the analysis of underlying transport phenomena in high-temperature catalytic reactors towards mass transfer for the case study that is presented, absorption and reaction kinetic limitations, further investigations at the microscale e.g. through the development of a microkinetic reaction mechanism are necessary.

Nowadays, computational capabilities and the increasing use of CFD codes enables reactor design and optimization of complex reactor geometries. The complexity of modeling tasks, computational cost as well as numerous modeling possibilities of commercial CFD tools make careful model selection and scrutinizing modeling assumptions as important as ever in order to find the model that suits a specific problem in an optimal way. An analysis of the kind 
presented in this contribution may lead to a priori not intuitive opportunities for process intensification as illustrated in the present example: having obtained a better understanding of the prevalence of convective, radiative and conductive heat transfer enables systematic improvements in the design and operation of single reactor compartments and the overall reactor based on these insights.

\section{Nomenclature}

$\alpha \quad$ component index: $\alpha \in\left[\mathrm{CH}_{4}, \mathrm{NH}_{3}, \mathrm{HCN}, \mathrm{N}_{2}, \mathrm{H}_{2}\right]$

$\chi_{i} \quad$ integrated term $i$ of the energy balance $/ \mathrm{W} \mathrm{m}^{-1}$

$\epsilon_{s} \quad$ surface emissivity / -

$\eta \quad$ wavenumber $/ \mathrm{cm}^{-1}$

$\kappa \quad$ radiative absorption coefficient $/ \mathrm{m}^{-1}$

$\kappa_{\eta, \alpha} \quad$ spectral absorption coefficient of component $\alpha / \mathrm{m}^{-1}$

$\kappa_{P, \alpha} \quad$ Planck mean absorption coefficient of component $\alpha / \mathrm{bar}^{-1} \mathrm{~m}^{-1}$

$\lambda \quad$ thermal conductivity $/ \mathrm{W} \mathrm{m}^{-1} \mathrm{~s}^{-1}$

Bo Boltzmann number / -

Gr Grashoff number / -

N Planck number / -

Re Reynolds number / -

$\mathrm{y}^{+} \quad$ wall $\mathrm{y}^{+} /-$

$\nu_{\alpha, i} \quad$ stoichiometric coefficient of species $\alpha$ in reaction $i /-$ 
$\Omega \quad$ set of all directions $s$ of the angular space

$\omega \quad$ normalized grid spacing $\omega:=N_{\max } / N_{i} /$ -

$\rho \quad$ density $/ \mathrm{kg} / \mathrm{m}^{3}$

$\sigma \quad$ Stefan-Boltzmann constant $/ \mathrm{W} \mathrm{m}^{-2} \mathrm{~K}^{-4}$

$\sigma_{\alpha} \quad$ source term of component $\alpha / \mathrm{kg} \mathrm{m}^{-3} \mathrm{~s}^{-1}$

$\tau \quad$ space time $\tau:=V_{\text {ref }} / F_{\text {ref }}(z=0) / \mathrm{s}$

$\tau^{*} \quad$ modified stress tensor $/ \mathrm{kg} \mathrm{m}^{-1} \mathrm{~s}^{-2}$

$\tau_{R} \quad$ residence time in the reactor $/ \mathrm{s}$

$\tilde{M}_{\alpha} \quad$ molar mass of component $\alpha / \mathrm{kg} \mathrm{m}^{-3}$

$A_{s} \quad$ catalyst surface $/ \mathrm{m}^{2}$

$c \quad$ speed of light $/ \mathrm{cm} \mathrm{s}^{-1}$

$c_{p} \quad$ heat capacity of the gas mixture $/ \mathrm{J} \mathrm{kg}^{-1} \mathrm{~K}^{-1}$

$D_{\alpha, \text { eff }}$ effective diffusivity coefficient for component $\alpha / \mathrm{m}^{2} \mathrm{~s}^{-1}$

$E^{\prime \prime} \quad$ lower state energy $/ \mathrm{cm}^{-1}$

$g \quad$ standard gravity $/ \mathrm{m} \mathrm{s}^{-2}$

$h \quad$ Planck constant / erg K

$h_{\alpha}^{0} \quad$ enthalpy of pure component $\alpha / \mathrm{J} \mathrm{kg}^{-1}$

$I \quad$ radiative intensity $/ \mathrm{W} \mathrm{m}^{-2}$

$I_{b} \quad$ radiative intensity of a black body $/ \mathrm{W} \mathrm{m}^{-2}$

$j_{y, \alpha} \quad$ diffusion flux in $y$ direction of component $\alpha / \mathrm{kg} \mathrm{m}^{-2} \mathrm{~s}^{-1}$ 


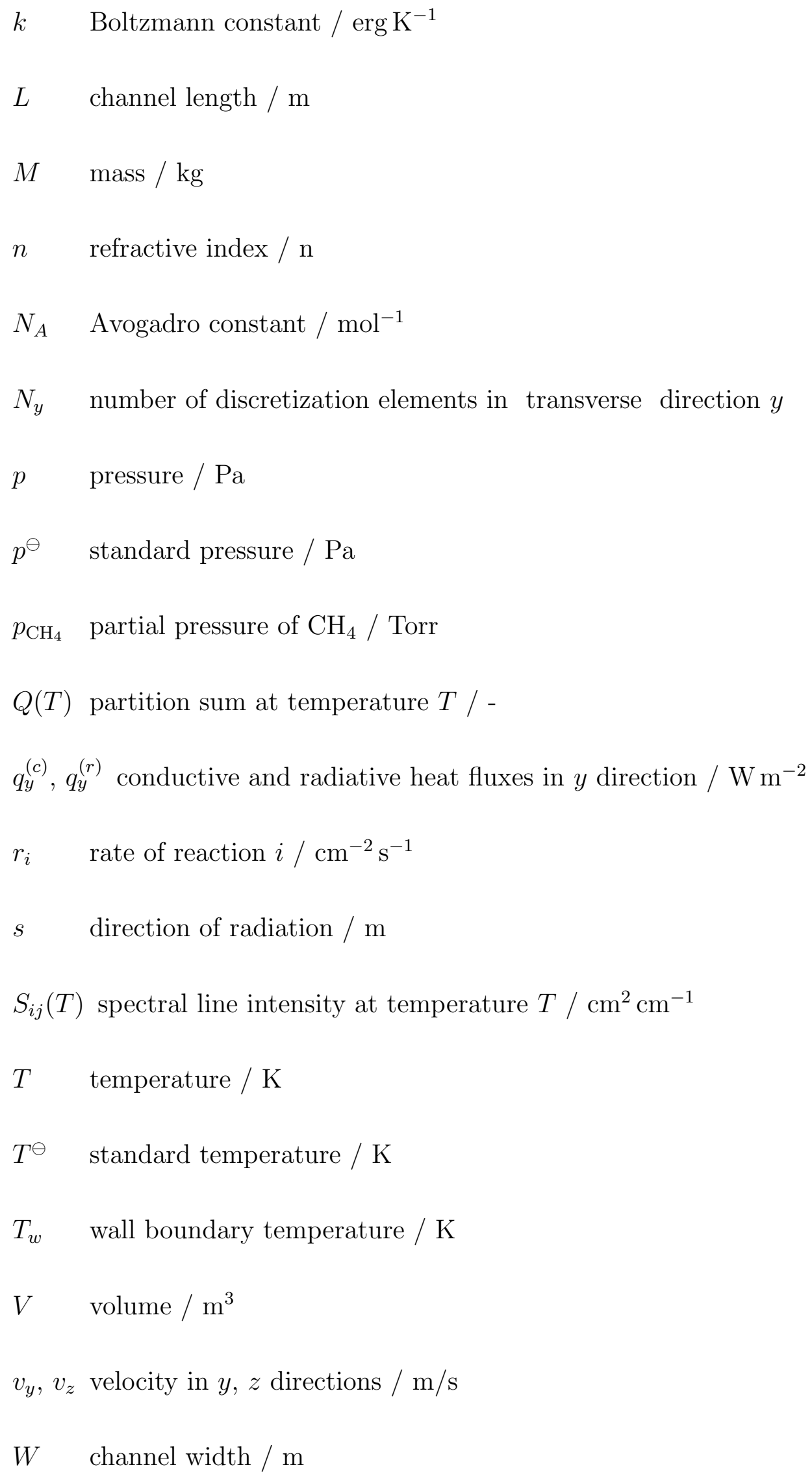


$w_{\alpha} \quad$ mass fraction of component $\alpha /-$

$w_{\tau} \quad$ total mass fraction $w_{\tau}:=M\left(\tau_{R}, z=L\right) / M\left(\tau_{R}=0, z=0\right) /-$

$x_{\mathrm{CH}_{4}}$ molar fraction of species $\mathrm{CH}_{4} /-$

$y \quad$ transverse coordinate of the reactor model / $\mathrm{m}$

$z \quad$ principle flow direction of the reactor model $/ \mathrm{m}$

BMA Blausäure aus Methan und Ammoniak (Ger.) - HCN from methane and ammonia

DAE differential algebraic system

PDE partial differential equation

RTE radiative transfer equation

SMR steam methane reforming

\section{Supporting Information}

This information is available free of charge via the internet at http://pubs.acs.org.

Discretization of the Species Mass Balance

Eqs $(\mathrm{S} 1)-(\mathrm{S} 4)$

\section{Acknowledgement}

The author Georg Liesche is also affiliated to the International Max Planck Research School (IMPRS) for Advanced Methods in Process Systems Engineering (Magdeburg). 


\section{References}

(1) Bosseboeuf, D. Energy Efficiency Trends and Policies In Industry - An Analysis Based on the ODYSSEE and MURE Databases; Enerdata: Grenoble, 2015.

(2) Bazzanella, A. M.; Ausfelder, F. Technology Study: Low carbon energy and feedstock for the European chemical industry; DECHEMA Gesellschaft für Chemische Technik und Biotechnologie e.V.: Frankfurt a.M., 2017.

(3) Petrasch, J.; Steinfeld, A. Dynamics of a Solar Thermochemical Reactor for SteamReforming of Methane. Chem. Eng. Sci. 2007, 62, 4214-4228.

(4) Z'Graggen, A.; Steinfeld, A. Hydrogen Production by Steam-Gasification of Carbonaceous Materials Using Concentrated Solar Energy - V. Reactor Modeling, Optimization, and Scale-Up. Int. J. Hydrogen Energy 2008, 33, 5484-5492.

(5) Mozdzierz, M.; Brus, G.; Sciazko, A.; Komatsu, Y.; Kimijima, S.; Szmyd, J. S. Towards a Thermal Optimization of a Methane/Steam Reforming Reactor. Flow Turbulence Combust. 2016, 97, 171-189.

(6) Bhat, S. A.; Sadhukhan, J. Process Intensification Aspects for Steam Methane Reforming: An Overview. AIChE J. 2009, 55, 408-422.

(7) Schwaab, M.; Alberton, A. L.; Fontes, C. E.; Bittencourt, R. C.; Pinto, J. C. Hybrid Modeling of Methane Reformers. 2. Modeling of the Industrial Reactors. Ind. Eng. Chem. Res. 2009, 48, 9376-9382.

(8) Lao, L.; Aguirre, A.; Tran, A.; Wu, Z.; Durand, H.; Christofides, P. D. CFD Modeling and Control of a Steam Methane Reforming Reactor. Chem. Eng. Sci. 2016, 148, 78-92.

(9) Yu, Z.; Cao, E.; Wang, Y.; Zhou, Z.; Dai, Z. Simulation of Natural Gas Steam Reforming Furnace. Fuel Process. Technol. 2006, 87, 695-704. 
(10) Olivieri, A.; Vegliò, F. Process Simulation of Natural Gas Steam Reforming: Fuel Distribution Optimisation in the Furnace. Fuel Process. Technol. 2008, 89, 622-632.

(11) Tran, A.; Aguirre, A.; Durand, H.; Crose, M.; Christofides, P. D. CFD Modeling of a Industrial-Scale Steam Methane Reforming Furnace. Chem. Eng. Sci. 2017, 171, $576-598$.

(12) Baukal, C. E. Heat Transfer in Industrial Combustion; CRC Press: Boca Raton, 2000.

(13) Specht, E. Wärme- und Stoffübertragung in der Thermoprozesstechnik: Grundlagen Berechnungen — Prozesse; Vulkan: Essen, 2014.

(14) Woods, D. R. Rules of Thumb in Engineering Practice; Wiley-VCH: Weinheim, 2007.

(15) Andersson, J. A General-Purpose Software Framework for Dynamic Optimization. Ph.D. dissertation, KU Leuven, Heverlee, Belgium, 2013.

(16) Gail, E.; Gos, S.; Kulzer, R.; Lorösch, J.; Rubo, A.; Sauer, M.; Kellens, R.; Reddy, J.; Steier, N.; Hasenpusch, W. Cyano Compounds, Inorganic. Ullmann's Encyclopedia of Industrial Chemistry, Wiley-VCH: Weinheim, 2000.

(17) Endter, F. Die technische Synthese von Cyanwasserstoff aus Methan und Ammoniak ohne Zusatz von Sauerstoff. Chem. Ing. Tech. 1958, 30, 305-310.

(18) Koberstein, E. Model Reactor Studies of the Hydrogen Cyanide Synthesis from Methane and Ammonia. Ind. Eng. Chem. Process Des. Develop. 1973, 12, 444-448.

(19) Hippel, L. v.; Bussek, C.; Arntz, D. (Degussa AG). Verfahren zur Herstellung von Blausäure. EP 0752390 B1, 1996.

(20) Mundhwa, M.; Parmar, R. D.; Thurgood, C. P. A Comparative Parametric Study of a Catalytic Plate Methane Reformer Coated with Segmented and Continuous Layers of Combustion Catalyst for Hydrogen Production. J. Power Sources 2017, 344, 85-102. 
(21) Howell, J. R.; Menguc, M. P.; Siegel, R. Thermal Radiation Heat Transfer, 5th ed.; CRC Press - Taylor and Francis: Boca Raton, 2010.

(22) Krause, E.; Schlichting, H.; Oertel, H. J.; Gersten, K. Grenzschicht-Theorie, 10th ed.; Springer: Berlin, 2013.

(23) Burgess, D. R. Thermochemical Data. In NIST Chemistry WebBook: NIST Standard Reference Database Number 69, Lindstrom, P. J., Mallard, W. G., Eds.; 2017.

(24) Diefenbach, M.; Brönstrup, M.; Aschi, M.; Schröder, D.; Schwarz, H. HCN Synthesis from Methane and Ammonia: Mechanisms of Pt+-Mediated C-N Coupling. J. Am. Chem. Soc. 1999, 121, 10614-10625.

(25) Hasenberg, D.; Schmidt, L. D. HCN Synthesis from $\mathrm{CH}_{4}$ and $\mathrm{NH}_{3}$ on Clean Rh. J. Catal. 1985, 91, 116-131.

(26) Hasenberg, D.; Schmidt, L. D. HCN synthesis from $\mathrm{CH}_{4}$ and $\mathrm{NH}_{3}$ on Platinum. J. Catal. 1986, 97, 156-168.

(27) Bird, R. B.; Stewart, W. E.; Lightfoot, E. N. Transport Phenomena, 2nd ed.; John Wiley and Sons: New York, 2007.

(28) Jischa, M. Konvektiver Impuls-, Wärme- und Stoffaustausch; Springer: Wiesbaden, 1982.

(29) Wilke, C. R. A Viscosity Equation for Gas Mixtures. J. Chem. Phys. 1950, $18,517$.

(30) Kee, R. J.; Dixon-Lewis, G.; Warnatz, J.; Coltrin, M. E.; Miller, J. A. A FORTRAN Computer Code Package for the Evaluation of Gas-Phase, Multicomponent Transport Properties. SAND86-8246 1986, 3-39.

(31) Fuller, E. N.; Schettler, P. D.; Giddings, J. C. A New Method for Prediction of Binary Gas Phase Diffusion Coefficients. J. Ind. Eng. Chem. 1966, 58, 19-27. 
(32) Leckner, B. Spectral and Total Emissivity of Water Vapor and Carbon Dioxide. Combust. Flame 1972, 19, 33-48.

(33) Kochanov, R. V.; Gordon, I. E.; Rothman, L. S.; Wcisło, P.; Hill, C.; Wilzewski, J. S. HITRAN Application Programming Interface (HAPI): A Comprehensive Approach to Working with Spectroscopic Data. J. Quant. Spectrosc. Radiat. Transfer 2016, 177, $15-30$.

(34) Zhang, H.; Modest, M. F. Evaluation of the Planck-Mean Absorption Coefficients from HITRAN and HITEMP Databases. J. Quant. Spectrosc. Radiat. Transfer 2002, 73, 649-653.

(35) Rothman, L. S.; Gordon, I. E.; Barber, R. J.; Dothe, H.; Gamache, R. R.; Goldman, A.; Perevalov, V. I.; Tashkun, S. A.; Tennyson, J. HITEMP, the High-Temperature Molecular Spectroscopic Database. J. Quant. Spectrosc. Radiat. Transfer 2010, 111, 21392150 .

(36) Rothman, L. S. et al. The HITRAN2012 Molecular Spectroscopic Database. J. Quant. Spectrosc. Radiat. Transfer 2013, 130, 4-50.

(37) Hindmarsh, A. C.; Brown, P. N.; Grant, K. E.; Lee, S. L.; Serban, R.; Shumaker, D. E.; Woodward, C. S. SUNDIALS: Suite of Nonlinear and Differential/Algebraic Equation Solvers. ACM Transactions on Mathematical Software (TOMS) 2005, 31, 363-396.

(38) Patankar, S. Numerical Heat Transfer and Fluid Flow; Taylor \& Francis: London, 1980.

(39) Liesche, G.; Sundmacher, K. Productivity versus Product Quality: Exploring the Limits of Autothermal Microchannel Reactors in Methane Steam Reforming. Chem. Eng. J. 2018, 10.1016/j.cej.2018.09.209.

(40) Graziani, F., Ed. Computational Methods in Transport: Verification and Validation; Springer: Berlin, 2008. 
(41) Sauer, J.; Bewersdorf, M.; Köstner, M.; Rinner, M.; Wolf, D. Hydrocyanic Acid (HCN) Production. In Handbook of Heterogeneous Catalysis, Ertl, G., Ed.; Wiley-VCH, 2008; pp 2592-2609.

(42) Chorkendorff, I.; Niemantsverdriet, J. W. Concepts of Modern Catalysis and Kinetics; Wiley-VCH: New York, 2017.

(43) Waletzko, N.; Schmidt, L. D. Modeling Catalytic Gauze Reactors: HCN Synthesis. AIChE J. 1988, 34, 1146-1156.

(44) Bremer, J.; Rätze, Karsten H. G.,; Sundmacher, K. $\mathrm{CO}_{2}$ Methanation: Optimal StartUp Control of a Fixed-Bed Reactor for Power-to-Gas Applications. AIChE J. 2017, 63, 23-31.

(45) Drazin, P. G.; Reid, W. H. Hydrodynamic Stability, 2nd ed.; Cambridge University Press: Cambridge, 2004.

(46) Pope, S. B. Turbulent Flows; Cambridge University Press: Cambridge, 2000.

(47) Kays, W.; Crawford, M.; Weigand, B. Convective Heat 83 Mass Transfer, 4th ed.; McGraw-Hill: New York, 2005.

(48) Verein Deutscher Ingenieure, VDI-Gesellschaft Verfahrenstechnik und Chemieingenieurwesen, VDI-Wärmeatlas, 11th ed.; Springer: Berlin, 2013.

(49) Levenspiel, O. Chemical Reaction Engineering; Wiley-VCH: New York, 1999.

(50) Chu, H.; Gu, M.; Zhou, H.; Liu, F. Calculations of Narrow-Band Transimissities and the Planck Mean Absorption Coefficients of Real Gases Using Line-by-Line and Statistical Narrow-Band Models. Front. Energy 2014, 8, 41-48. 


\section{For Table of Contents Only}

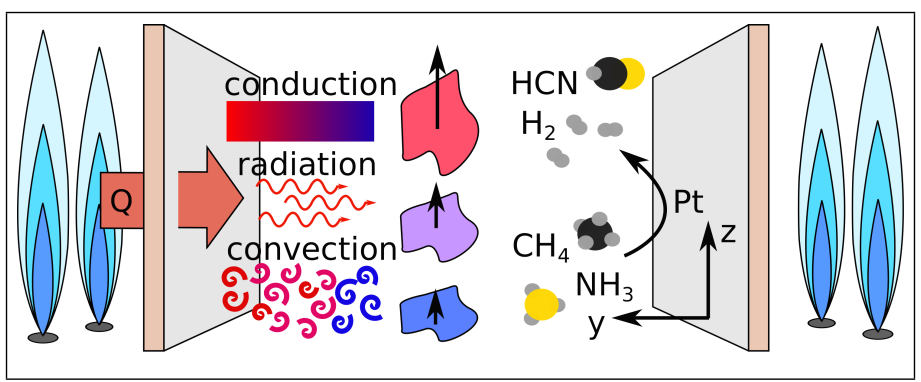

